\title{
Presynaptic Neuronal Nicotinic Receptors Differentially Shape Select Inputs to Auditory Thalamus and Are Negatively Impacted by Aging
}

\author{
Sarah Y. Sottile, ${ }^{1}$ Troy A. Hackett, ${ }^{3}{ }^{\odot}$ Rui Cai, ${ }^{1}{ }^{-}$Lynne Ling, ${ }^{1}{ }^{-}$Daniel A. Llano, ${ }^{4,5}$ and $\odot$ Donald M. Caspary ${ }^{1,2}$ \\ ${ }^{1}$ Department of Pharmacology and ${ }^{2}$ Department of Surgery, Division of Otolaryngology, Southern Illinois University School of Medicine, Springfield, \\ Illinois 62702, ${ }^{3}$ Department of Hearing and Speech Sciences, Vanderbilt University Medical Center, Nashville, Tennessee 37232, and ${ }^{4}$ Neuroscience \\ Program and ${ }^{5}$ Department of Molecular and Integrative Physiology, University of Illinois at Urbana-Champaign, Urbana, Illinois 61801
}

Acetylcholine (ACh) is a potent neuromodulator capable of modifying patterns of acoustic information flow. In auditory cortex, cholinergic systems have been shown to increase salience/gain while suppressing extraneous information. However, the mechanism by which cholinergic circuits shape signal processing in the auditory thalamus (medial geniculate body, MGB) is poorly understood. The present study, in male Fischer Brown Norway rats, seeks to determine the location and function of presynaptic neuronal nicotinic ACh receptors (nAChRs) at the major inputs to MGB and characterize how nAChRs change during aging. In vitro electrophysiological/optogenetic methods were used to examine responses of MGB neurons after activation of nAChRs during a paired-pulse paradigm. Presynaptic $\mathrm{nAChR}$ activation increased responses evoked by stimulation of excitatory corticothalamic and inhibitory tectothalamic terminals. Conversely, nAChR activation appeared to have little effect on evoked responses from inhibitory thalamic reticular nucleus and excitatory tectothalamic terminals. In situ hybridization data showed nAChR subunit transcripts in GABAergic inferior colliculus neurons and glutamatergic auditory cortical neurons supporting the present slice findings. Responses to nAChR activation at excitatory corticothalamic and inhibitory tectothalamic inputs were diminished by aging. These findings suggest that cholinergic input to the MGB increases the strength of tectothalamic inhibitory projections, potentially improving the signal-to-noise ratio and signal detection while increasing corticothalamic gain, which may facilitate top-down identification of stimulus identity. These mechanisms appear to be affected negatively by aging, potentially diminishing speech perception in noisy environments. Cholinergic inputs to the MGB appear to maximize sensory processing by adjusting both top-down and bottom-up mechanisms in conditions of attention and arousal.

Key words: aging; attention; auditory; nicotinic; sensory processing; thalamus

\section{Significance Statement}

The pedunculopontine tegmental nucleus is the source of cholinergic innervation for sensory thalamus and is a critical part of an ascending arousal system that controls the firing mode of thalamic cells based on attentional demand. The present study describes the location and impact of aging on presynaptic neuronal nicotinic acetylcholine receptors (nAChRs) within the circuitry of the auditory thalamus (medial geniculate body, MGB). We show that nAChRs are located on ascending inhibitory and descending excitatory presynaptic inputs onto MGB neurons, likely increasing gain selectively and improving temporal clarity. In addition, we show that aging has a deleterious effect on nAChR efficacy. Cholinergic dysfunction at the level of MGB may affect speech understanding negatively in the elderly population.

\section{Introduction}

Numerous studies have identified a loss of attentional mechanisms as a critical factor in age-related loss of speech understanding (Schieber, 2003; Harris et al., 2012; Humes et al., 2012). One

Received June 27, 2017; revised Oct. 5, 2017; accepted Oct. 11, 2017.

Author contributions: S.Y.S., T.A.H., R.C., L.L., D.A.L., and D.M.C. designed research; S.Y.S., T.A.H., R.C., and L.L. performed research; S.Y.S., T.A.H., R.C., and D.M.C. contributed unpublished reagents/analytic tools; S.Y.S., T.A.H., and R.C. analyzed data; S.Y.S., T.A.H., R.C., D.A.L., and D.M.C. wrote the paper. may compensate for decline in ascending auditory signal quality through increased use of cognitive resources by focusing their attention on important acoustic stimuli (Bertoli et al., 2001, Alain 
et al., 2004; Bidelman et al., 2014). Unfortunately, even after adjusting for age-related temporal deficits, older adults are less able to compensate for degraded auditory input by using attentional strategies to help them encode the stimulus (Harris et al., 2012). The overall deficit in hearing seen in presbycusis is then explained best, not only by a loss of ascending auditory signal fidelity, but also by loss of higher-order cognitive abilities, including attention (Wingfield et al., 2005).

Convergence of the functions mediated by top-down and bottom-up processes are crucial to performance in tasks requiring continuous attention, not only in the auditory system, but all sensory modalities (Sarter et al., 2001). It is likely that age-related neural alterations seen in presbycusis are not limited to any single central auditory structure, but rather occur in the functional connections between regions. In this study, we examine nicotinic cholinergic circuitry within the medial geniculate body (MGB) and posit that top-down and bottom-up processing are modulated in part by cholinergic systems that can direct attention to relevant incoming auditory information.

To better understand how the MGB shapes the neural representation of sound, we must understand how response properties are generated and altered, as well as the nature of the ascending and descending excitatory and inhibitory inputs. Responses of MGB neurons are dictated primarily by ascending excitatory and inhibitory sensory input from the inferior colliculus (IC), excitatory projections descending from the auditory cortex (AC), and inhibitory projections descending from the thalamic reticular nucleus (TRN; Bartlett and Smith, 1999; He, 2003; Yu et al., 2004; Bartlett and Wang, 2011; Ito and Oliver, 2012; Smith et al., 2012, Cotillon-Williams et al., 2008). AC projections to the ventral MGB show small terminal endings originating in L6, whereas L5 neurons are associated with large endings that terminate in dorsal MGB (Bajo et al., 1995; Rouiller and Welker, 2000; He, 2003; Rouiller and Durif, 2004).

The pedunculopontine nucleus (PPTg) and the laterodorsal tegmental nucleus are brainstem nuclei that collectively comprise the pontomesencephalic tegmentum (PMT), which provides cholinergic input to the MGB (Morley and Kemp, 1981; Woolf, 1991; Schofield et al., 2011). The PMT has been implicated in many systems responsible for wakefulness, sleep, and attention (Jones, 1991; Kozak et al., 2005; Boucetta et al., 2014). In the context of the auditory system, PMT neurons are critical in sensory gating and detecting novel/difficult-to-identify signals through a number of direct and indirect descending circuits (Schofield et al., 2011). The AC is known to have direct axonal projections to the PMT cells themselves (Schofield et al., 2011). Collectively, these top-down pathways provide the basis for augmenting the output of the PMT cholinergic system.

Cholinergic circuits facilitate top-down processing through activation of neuronal nicotinic (nAChRs) and muscarinic (mAChRs) acetylcholine (ACh) receptors and act to enhance transmission of sensory signals, especially under taxing attentional conditions when there is an unfavorable signal-to-noise ratio. Numerous studies have shown that nAChRs exist preferentially on presynaptic terminals, where they act to increase neurotransmitter release (Wonnacott, 1997; Jensen et al., 2005; Dani

The authors declare no competing financial interests.

Correspondence should be addressed to Prof. Donald M. Caspary, Department of Surgery, Division of Otolaryngology, Southern Illinois University School of Medicine, 801 N. Rutledge St., Springfield, IL 62702. E-mail: dcaspary@siumed.edu.

DOI:10.1523/JNEUROSCI.1795-17.2017

Copyright $\odot 2017$ the authors $\quad 0270-6474 / 17 / 3711378-13 \$ 15.00 / 0$ and Bertrand, 2007; Cox et al., 2008). The presence of differing $\alpha$ and $\beta \mathrm{nAChR}$ subunits contributes to agonist affinity and calcium permeability (Quick and Lester, 2002), with $\beta 2$-containing receptors having higher affinity for nicotinic agonists than $\beta 4$ containing nAChRs (Luetje et al., 1991). nAChRs have been implicated in a wide range of neurological dysfunctions associated with aging. Cholinergic systems are disrupted in diseases associated with cognitive deficits, including Alzheimer's disease and Parkinson's disease (Bartus et al., 1982; Aubert et al., 1992). The current study aimed to identify the presence and location of $\mathrm{nAChRs}$ in the MGB circuitry, defining where cholinergic inputs act, as well as how aging alters these systems. Age-related cholinergic dysfunction in the PMT-MGB attentional circuit may underpin a mechanism contributing to the pathology of presbycusis, being one factor in the loss of normal attentional mechanisms in the age-related loss of speech understanding.

\section{Materials and Methods}

Animals. Young adult (4-6 months old) or aged (28-32 months old) Fischer Brown Norway (FBN) rats were obtained from the National Institute on Aging (National Institutes of Health) rodent resource colonies, where they were individually housed on a reversed 12:12 h lightdark cycle with ad libitum access to food and water. Procedures were performed in accordance with guidelines and protocols approved by the Southern Illinois University School of Medicine Animal Care and Use Committee.

Slice preparation. Young adult and aged FBN rats were anesthetized using isoflurane and decapitated. Brains were quickly removed and submerged in cold $\left(1-2^{\circ} \mathrm{C}\right)$ artificial CSF $(\mathrm{aCSF})$ maintained at $\mathrm{pH} 7.4$ by bubbling with carbogen $\left(95 \% \mathrm{O}_{2} / 5 \% \mathrm{CO}_{2}\right)$. The aCSF composition was as follows (in mM): $125 \mathrm{NaCl}, 3 \mathrm{KCl}, 1 \mathrm{MgCl}_{2}, 1.23 \mathrm{NaH}_{2} \mathrm{PO}_{4}, 2 \mathrm{CaCl}_{2}, 26$ $\mathrm{NaHCO}_{3}$, and 10 glucose. Colliculothalamocortical brain slices (250$300 \mu \mathrm{m}$ ) were made as described in Llano et al. (2014) using a Vibratome (Pelco) and immediately incubated for $15 \mathrm{~min}$ at physiological temperature $\left(37^{\circ} \mathrm{C}\right)$, followed by $45 \mathrm{~min}$ at room temperature $\left(20-22^{\circ} \mathrm{C}\right)$ in carbogen-bubbled aCSF. Individual slices were transferred to an immersion recording chamber $(2 \mathrm{ml})$ placed on an upright microscope (BX50WI; Olympus) equipped with infrared differential interference contrast image filters and viewed with a $40 \times$ water-immersion objective. Slices were perfused at a rate of $2-3 \mathrm{ml} / \mathrm{min}$ with aCSF bubbled with carbogen at room temperature.

Whole-cell recordings. Patch-clamp recordings were performed in the whole-cell configuration using 4-6 $\mathrm{M} \Omega$ fire-polished pipettes pulled from borosilicate glass $(1.1 \mathrm{~mm}$ inner diameter, $1.7 \mathrm{~mm}$ outer diameter; Garner Glass). The internal patch pipette solution used for studying excitatory responses contained the following (in $\mathrm{mM}$ ): 140.0 potassium gluconate, $1 \mathrm{NaCl}, 2 \mathrm{MgCl}_{2}, 10 \mathrm{HEPES}, 2 \mathrm{Mg}$-ATP, $0.3 \mathrm{Na}-\mathrm{GTP}$, and 6.88 $\mathrm{KOH}$ at $300 \mathrm{mOsm}$ and $\mathrm{pH}$ 7.3. The internal patch pipette solution used for studying inhibitory responses contained the following (in $\mathrm{mM}$ ): 120.0 cesium methanesulfonate $\left(\mathrm{CsCH}_{3} \mathrm{SO}_{3}\right), 2 \mathrm{CsCl}, 5 \mathrm{NaCl}, 1.5 \mathrm{MgCl}_{2}, 10$ HEPES, 10 EGTA, 5 TEA-Cl, $2.5 \mathrm{Mg}$-ATP, $0.3 \mathrm{Na}-\mathrm{GTP}, 5$ QX-314, and $0.3 \mathrm{CsOH}$ at $300 \mathrm{mOsm}$ and $\mathrm{pH}$ 7.3. An Axoclamp 2B amplifier (Molecular Devices) was used and cells were recorded in the continuous current or voltage-clamp modes. In voltage-clamp conditions, cells were held at $-70 \mathrm{mV}$ to study excitatory responses and at $+20 \mathrm{mV}$ to study inhibitory responses. The patch pipette was positioned in the MGB and neurons were viewed with the Olympus microscope. Whole-cell capacitance, input resistance, and series resistance were determined by application of a $5 \mathrm{mV}$ square pulse. Exclusion criteria included: (1) a resting membrane potential (RMP) more depolarized than $-60 \mathrm{mV}$, (2) series resistance $>20 \mathrm{M} \Omega$, or (3) a resting input resistance $<100 \mathrm{M} \Omega$. Generated transistor-transistor logic (TTL) pulses, voltage commands, acquisition, and display of the recorded signals were achieved using the Clampex program (Molecular Devices). For the paired-pulse experiments, an interstimulus interval of $120 \mathrm{~ms}$ was used for all experiments based on the extensive studies of Bartlett and Smith (2002). EPSP amplitudes were measured from the base of the rising phase to the EPSP peak. Paired- 
pulse depression occurred if the amplitude of the second EPSP was smaller than the first. Paired-pulse facilitation occurred when the amplitude of the second EPSP was larger than the first.

Drug application. To block muscarinic cholinergic receptors, all experiments were done in the presence of atropine ( $20 \mu \mathrm{M}$; Sigma-Aldrich) which was added to the aCSF bath solution. For experiments analyzing spontaneous events, a patch pipette containing varying concentrations of ACh was positioned $10-20 \mu \mathrm{m}$ from the patched cell using an on-screen scale bar and the drug was pressure ejected (2-4 PSI) from a Picospritzer (General Valve). All other pharmacological agents, ACh (Sigma-Aldrich), mecamylamine (10 $\mu \mathrm{m}$; Tocris Bioscience), dihydro- $\beta$-erythroidine hydrobromide ( $\mathrm{DH} \beta \mathrm{E}, 100 \mathrm{~nm}$; Tocris Bioscience), gabazine (40 $\mu \mathrm{M}$; SR95531; Sigma-Aldrich), DL-APV sodium salt (50 $\mu \mathrm{m}$; Abcam), and DNQX (20 $\mu \mathrm{M}$; Abcam) were bath applied as noted.

Optogenetics. Adenoviral vectors (AAV-CaMKIIa-hChR2(H134R)eYFP, AAV serotype 5) were obtained from the University of North Carolina Vector Core. Young adult FBN rats were anesthetized using ketamine $(105 \mathrm{mg} / \mathrm{kg}) / x y l a z i n e(7 \mathrm{mg} / \mathrm{kg})$ and maintained with isoflurane $(0.5-1 \%)$ throughout the surgery. Viral vectors were then injected intracranially into IC or AC using Neurostar stereotaxic drill and injection instruments (Neurostar). A small hole was drilled into the skull and the dura mater was removed. Coordinates of the injection sites were as follows: primary AC layers 5 and 6 (L5 and L6), entry at $22^{\circ}$ angle laterally and $(-8.93,-1.8,4.37 \mathrm{~mm}$ relative to bregma); central nucleus of the IC, entry at $22^{\circ}$ angle caudally and $(-4.75,7.04,5.52)$. Animals were allowed to recover for $\sim 21 \mathrm{~d}$ to allow for viral expression of the humanized channel rhodopsin [hChR2(H134R)] and eYFP expressed under the control of a calmodulin-dependent protein kinase II (CaMKIIa)-dependent promoter at the level of terminals in MGB (Cardin et al., 2010; Zhang et al., 2010).

Slices were made to maintain as much connectivity between the auditory structures as possible (for details, see Llano et al., 2014). A blue (470 $\mathrm{nm}$ ) fiber-coupled LED (Thorlabs) was used to activate hChR2 in the slice preparation. A fiber-optic cannula ( $2.5 \mathrm{~mm}$ SS ferrule, $200 \mu \mathrm{m}$ core, 0.39 numerical aperture, $\mathrm{L}=20 \mathrm{~mm}$ ) was placed directly above the slice over the area of the patched cell. LED was triggered using a TTL pulse controlled through the Clampex software.

Immunohistochemistry. During recording, cells were filled with $1 \%$ Neurobiotin 488 (Vector Laboratories). Immediately after recording, slices were fixed in $4 \%$ paraformaldehyde overnight and then moved to $0.01 \mathrm{~m}$ PBS the following day. Slices were not resectioned $(300 \mu \mathrm{m})$ and were stained using a protocol similar to Káradóttir and Atwell (2006). Free-floating slices were processed in parallel and incubated for $4 \mathrm{~h}$ in blocking solution containing PBS with $1.5 \%$ of normal donkey serum and $3 \%$ bovine serum albumin. Sections were transferred to primary antibody solution containing monoclonal mouse anti-vesicular glutamate transporter 1 (VGlut1) antibody (1:750; Millipore) and rabbit anti$\mathrm{nAChR} \beta 2$ antibody (1:250; Millipore) and incubated overnight at room temperature. After washing with PBS, sections were incubated with secondary antibodies as follows: donkey anti-mouse IgG (Alexa Fluor 647; 1:150 Jackson ImmunoResearch), donkey anti-rabbit IgG (Alexa Fluor 594; 1:150; Jackson ImmunoResearch) for $4 \mathrm{~h}$ at room temperature. As a negative control, the primary antibody was omitted and no immunolabeling was observed. After PBS washing, the sections were mounted onto slides and coverslipped with VectaShield (Vector Laboratories). After imaging with a Zeiss LSM 780 confocal microscope, colors were uniformly adjusted by processing with Zen imaging software to improve visibility. Anti-nAChR $\beta 2$ antibody (1:250; Millipore) was verified using brain sections from nAChR $\beta 2$ knock-out (KO) mice (B6.129S7Chrnb2 $\left.{ }^{\mathrm{tm} 1 \mathrm{Mdb}} / \mathrm{MMRRC}\right)$ obtained from the Mutant Mouse Resource and Research Center (MMRRC), University of North Carolina (Chapel Hill, NC). Genotyping of offspring was performed before postnatal day 21. Genotyping was performed using the following primers: $5^{\prime}-\mathrm{GAG}$ ACT AGT GAG ACG TGC TAC TTC CAT TTG-3'; $5^{\prime}$-CTC TGA CTG TAA AGG CAG TGG TTG CTA TAG-3'; and 5'-TAG CTA TTG ACG TCT TTA AGA TCC-3' (Xu et al., 1999). Only wild-type (WT) and $\beta 2 \mathrm{KO}$ mice were used in the antibody validation. Paired WT and $\beta 2 \mathrm{KO}$ mice ( 3 months old) were perfused with $4 \%$ of paraformaldehyde and regions of interest were sectioned at $30 \mu \mathrm{m}$. The resulting images from

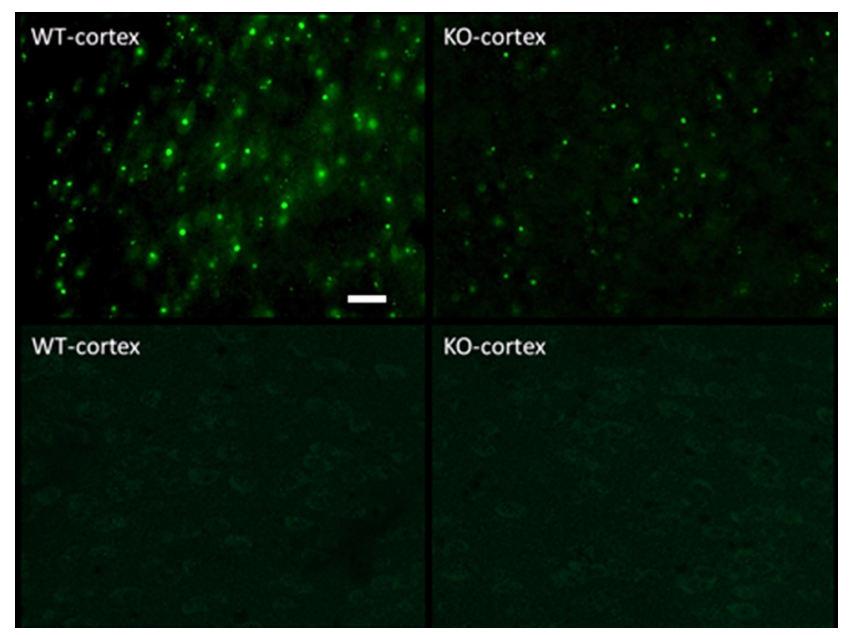

Figure 1. $\mathrm{nAChR} \beta 2$ antibody labeling in WT and $\beta 2 \mathrm{KO}$ mouse model. Immunofluorescence data in cortex of WT and $\beta 2$ KO mouse model. Polyclonal rabbit anti-AChR $\beta 2$ antibody (1:250, AB15325; Millipore) was used to label $\beta 2$-containing nAChRs. WT shows greater $\beta 2$ staining compared with $\mathrm{KO}$. Remaining $\beta 2$ immunolabel in $\mathrm{KO}$ is confined to nuclei. Negative controls in both show no $\beta 2$ staining. Scale bar, $10 \mu \mathrm{m}$.

\section{Table 1. Details of riboprobes targeted by FISH}

\begin{tabular}{lllll}
\hline Marker & Protein & Gene & Accession No. & Position \\
\hline $\begin{array}{c}\text { Glutamatergic } \\
\text { neuron }\end{array}$ & $\begin{array}{c}\text { Vesicular glutamate } \\
\text { transporter 1 }\end{array}$ & $\begin{array}{c}\text { Slc17a7 } \\
\text { (VGluT1) }\end{array}$ & NM_053859.2 & 529-1630 \\
GABAergic neuron & $\begin{array}{c}\text { Vesicular GABA/ } \\
\text { glycine transporter }\end{array}$ & $\begin{array}{c}\text { S/C32a1 } \\
(\text { VGAT) }\end{array}$ & NM_031782.1 & 288-1666 \\
$\begin{array}{c}\alpha 4 \text { nAChR subunit } \\
\beta 2 \text { nAChR subunit }\end{array}$ & $\begin{array}{c}\alpha 4 \text { nAChR subunit } \\
\text { ChAChR subunit }\end{array}$ & $\begin{array}{ll}\text { Chrna4 } \\
\text { ChAC }\end{array}$ & NM_024354.1 & 1001-1878 \\
\hline
\end{tabular}

$\mathrm{WT}$ and $\beta 2 \mathrm{KO}$ showed stronger $\beta 2$ staining in WT, whereas much weaker staining still appeared on $\beta 2 \mathrm{KO}$ section that was localized to nuclei (Fig. 1). The non-nuclear $\beta 2$ staining, seen only in the WT, strongly colocalized with a previously verified $\alpha 4 \mathrm{nAChR}$ antibody. All fluorescent imaging was performed using a Zeiss LSM 780 confocal laser scanning microscope.

FISH. FISH assays were conducted using custom riboprobes designed and manufactured by Advanced Cell Diagnostics (ACD) \{Wang et al., 2012 \#3928\} (Table 1). The assay (RNAscope) uses a proprietary signal amplification and background suppression methodology. Briefly, after a 30 min protease permeabilization step, 2 independent probes (double $\mathrm{Z}$ probe) were hybridized for $2 \mathrm{~h}$ to each target sequence ( $\sim 20$ probe pairs per target molecule). The lower region of each probe is complementary to the target sequence and the upper region is a 14-base tail sequence. The dual probe construct provides a 28 -base binding site for the preamplifiers, which were built up during a multistage amplification cycle. In the final step, fluorescent conjugates were bound to each of the 20 binding sites on each preamplifier. All incubation steps were performed at $40^{\circ} \mathrm{C}$ in a hybridization oven (HybEZ; ACD) using the RNAscope Multiplex Fluorescent Reagent kit according to the manufacturer's instructions for fresh-frozen brain tissue. As a negative control, sections were incubated in buffer solutions that did not contain riboprobes and revealed no significant labeling in any channel. FISH combined different sets of markers for AC (VGluT1, $\beta 2$, and $\alpha 4)$ and IC (VGAT, $\beta 2$, and $\alpha 4)$. Sections were counterstained with DAPI (30 s) to facilitate identification of brain regions and nuclei.

Image acquisition and analyses. Wide-field fluorescence images and image montages of FISH-labeled sections were obtained with a Nikon 90i epifluorescence microscope and Hamamatsu Orca 4.0 CCD camera controlled by Nikon Elements AR software using $20 \times, 40 \times$, and $100 \times$ objectives. Exposure parameters for each color channel were maintained at the same levels across all samples to standardize signal intensity. Images were assembled into figures using Adobe Illustrator CS6. The $40 \times$ and 

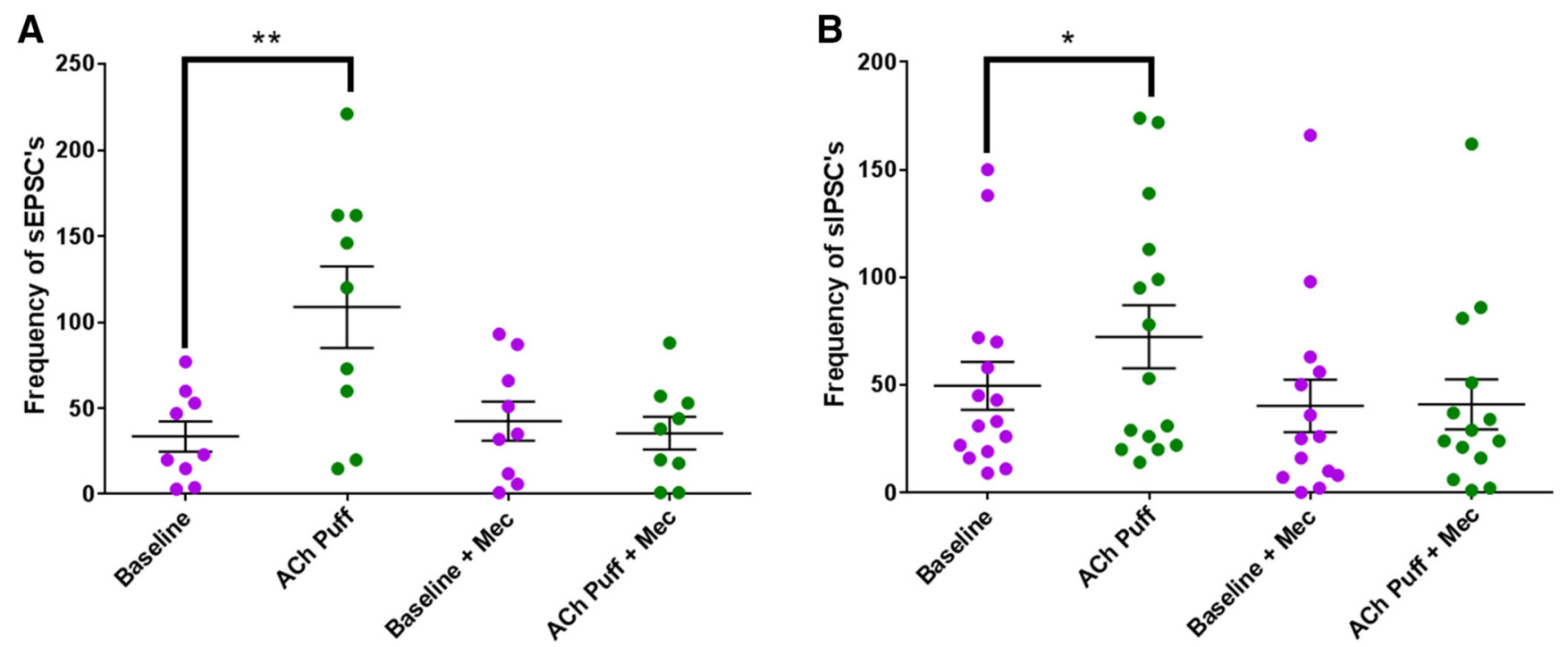

Figure 2. $\mathrm{nAChR}$ activation increases IPSC and EPSC frequency. Spontaneous events were recorded using whole-cell patch-clamp techniques in the presence of atropine (20 $\mu \mathrm{M})$ and either gabazine $(40 \mu \mathrm{m})$ to isolate sEPSCs $(\boldsymbol{A})$ or APV $(50 \mu \mathrm{m})$ and DNQX $(20 \mu \mathrm{M})$ to isolate sIPSCs $(\boldsymbol{B})$. Each group is representative of $20 \mathrm{~s}$ taken during the baseline condition (purple) immediately after application of a $1 \mathrm{~mm}$ ACh puff (green) and after the addition of the nAChR antagonist mecamylamine (10 $\mu \mathrm{m}$ ) to the bath solution. ACh increased the frequency, but not the amplitude (data not shown), of both sIPSCs and sEPSCs. (sEPSCs: $n=9$ neurons, sIPSCs: $n=15$ neurons). Paired $t$ tests were used for statistical analysis; ${ }^{* *} p<0.01,{ }^{*} p<0.05$.

$100 \times$ images were created from $z$-plane image stacks collapsed to two dimensions using an Extended Depth of Focus plugin to the Nikon Elements software.

Data and statistical analyses. Electrophysiology data were recorded using Clampex software (Molecular Devices). Responses to ACh were analyzed offline using Clampfit 10.6 or Mini Analysis (Synaptosoft, Inc., Fort Lee, NJ). All paired-pulse responses were analyzed in reference to S1 amplitude and paired-pulse ratio. All included data points are within 2 SDs of the mean. Paired Student's $t$ tests or repeated-measures mixed ANOVAs were performed using GraphPad Prism software. A significance level of 0.05 was used for all statistical tests. All values are expressed as means \pm SEM.

\section{Results}

\section{Electrical stimulation of the four major MGB inputs}

The four primary inputs to MGB are both excitatory and inhibitory projections ascending from IC, excitatory projections from $\mathrm{AC}$, and inhibitory projections from TRN. In addition to these, there are cholinergic projections from PMT in the brainstem. Theoretically, ACh released from the brainstem may act presynaptically on terminals originating from any one or more of the four major inputs.

To determine where presynaptic nAChRs exist, we first analyzed the effect of local ACh application on spontaneous excitatory and inhibitory events. For this, a MGB neuron in either the ventral or dorsal subdivision was patched and a second pipette filled with $1 \mathrm{~mm}$ ACh was placed $10-20 \mu \mathrm{m}$ away from the cell using an on-screen scale bar. Neurons in the medial subdivision of MGB were excluded because of diversity of inputs and outputs from outside of the IC and AC to this region (LeDoux et al., 1990). ACh was pressure ejected for $100 \mathrm{~ms}$ in the local area of the cell and total numbers and amplitude of EPSCs/IPSCs were recorded for subsequent analysis. Excitatory or inhibitory responses were isolated pharmacologically by bath application of either gabazine $(40 \mu \mathrm{M})$ to block $\mathrm{GABA}_{\mathrm{A}}$ receptors or APV (50 $\mu \mathrm{M})$ and DNQX $(20 \mu \mathrm{M})$ to block NMDA and AMPA receptors, respectively. After application of $1 \mathrm{~mm} \mathrm{ACh}$, we saw no significant differences in amplitude (EPSC, baseline amplitude: $16.06 \pm$ $1.33 \mathrm{pA}$, EPSC, ACh: $15.83 \pm 0.85 \mathrm{pA} ; p=0.87$; IPSC, baseline amplitude: $16.34 \pm 0.46 \mathrm{pA}$, IPSC, ACh $17.36 \pm 0.51 \mathrm{pA} ; p=$
$0.17)$, but a significant increase in frequency of both excitatory and inhibitory spontaneous events (Fig. 2). On the excitatory side, the total number of EPSCs in a $60 \mathrm{~s}$ period increased from $35.9 \pm 9.9$ to $156 \pm 54.0$ immediately after ACh application (Fig. $2 A)$. More modest inhibitory changes showed total numbers of IPSCs increased from $49.5 \pm 11.2$ to $72.3 \pm 14.7$ (Fig. $2 B$ ). These increases were blocked by addition of the nAChR antagonist mecamylamine $(10 \mu \mathrm{M})$ to the bath solution. Although cell morphology between the subdivisions differs, the intrinsic membrane properties of the neurons have been shown to be similar (Bartlett and Smith, 1999, Sottile et al., 2017). We do not see significant differences in the ability of ACh to modulate spontaneous events between subdivisions. Collectively, these findings suggest that presynaptic nAChRs exist on both glutamatergic and GABAergic terminals entering the MGB, although these data do not indicate the origin of these terminals/projections.

To probe this question further, a paired-pulse paradigm was implemented using paired electrical pulses delivered via a bipolar platinum-stimulating electrode. The electrode was placed either on ascending or descending fibers entering the MGB and responses to stimulation were studied in the absence or presence of ACh. Responses to pairs or trains of electrical stimuli from each of the synaptic inputs to MGB have been previously well studied by Bartlett and Smith (2002) and the present protocol was based on their findings. For excitatory projections from AC, a stimulating electrode was placed in the descending radiations to MGB. Excitatory responses were isolated using gabazine $(40 \mu \mathrm{M})$ to block all inhibitory responses, as described above. Similar to Bartlett and Smith (2002), stimulation of descending AC projections almost always produced paired-pulse facilitation (Fig. $3 A$ ), with an average S1 amplitude of $39.0 \pm 3.3 \mathrm{pA}$. Once a baseline response was established, $1 \mu \mathrm{M}$ ACh was bath applied for $2 \mathrm{~min}$, allowing for activation of nAChRs present in the circuitry. If presynaptic nAChRs are present, then presynaptic calcium loading should occur, priming the terminal for greater release of neurotransmitter. Bath application of ACh increased average S1 amplitude evoked by stimulation of glutamatergic AC projec- 
A

\section{Excitatory Corticothalamic Input}

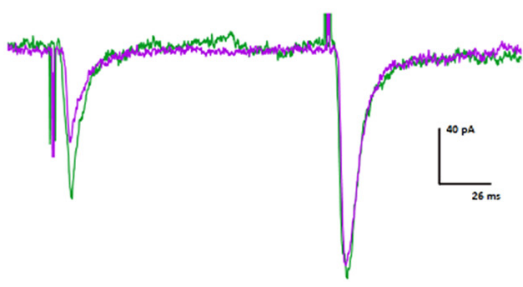

D
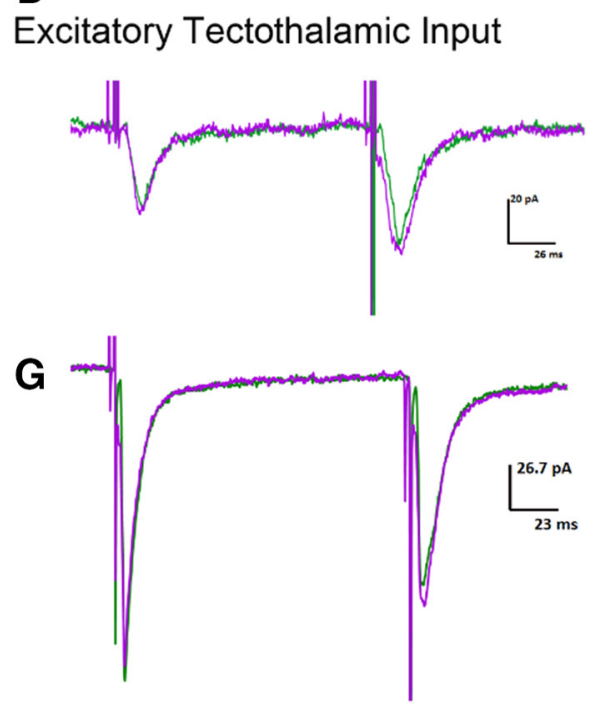

B

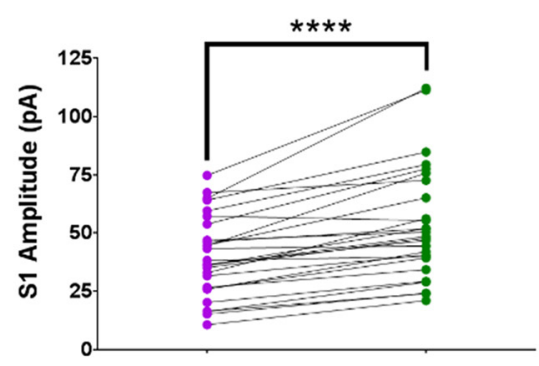

E

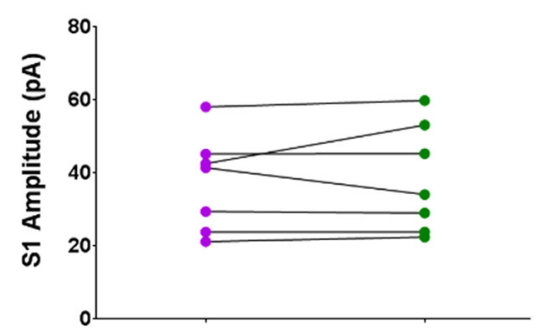

H

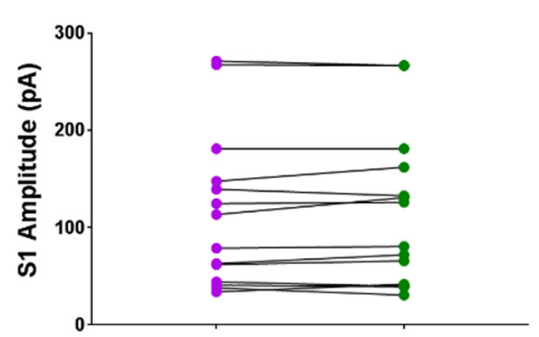

C

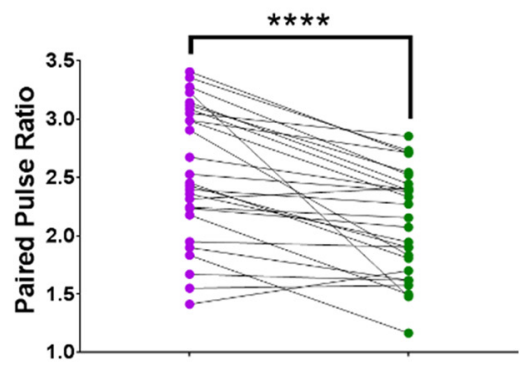

F

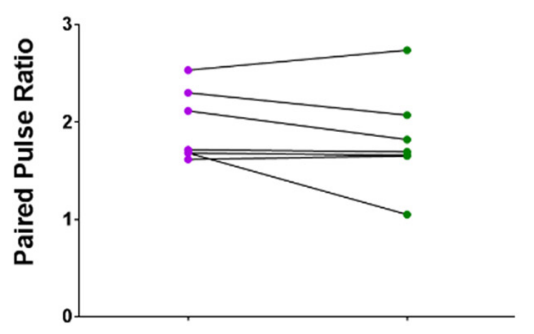

I

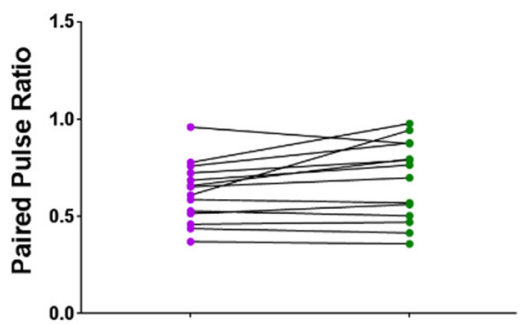

Figure 3. Activation of nAChRs enhances glutamate release at corticothalamic terminals, but has no consistent effect at tectothalamic terminals. Excitatory currents elicited from electrical stimulation of the descending fibers from AC or ascending IC fibers were recorded from MGB neurons in the presence of atropine (20 $\mu \mathrm{M})$ and gabazine (40 $\mu \mathrm{M})$. $\boldsymbol{A}-\boldsymbol{C}$, Corticothalamic input. Paired-pulse facilitation was exhibited from all neurons studied $(\boldsymbol{A})$. Bath application of $1 \mu \mathrm{m} A C$ caused an increase in the amplitude of $S 1(\boldsymbol{B})$ and a decrease in the paired-pulse ratio $(\boldsymbol{C})(\boldsymbol{n}=27)$. Paired $t$ tests were used for statistical analysis; ${ }^{* * * *} p<0.0001$. $\boldsymbol{D}-\boldsymbol{I}$, Tectothalamic input. Exemplars $(\boldsymbol{D}, \boldsymbol{G})$ and connected dot plots $(\boldsymbol{E}, \boldsymbol{F}, \boldsymbol{H}, \boldsymbol{I})$ show that baseline stimulation (purple) exhibits paired-pulse depression (G) in $\sim 70 \%$ of the neurons studied (14/21) and weak paired-pulse facilitation (D) in $\sim 30 \%$ of the neurons studied ( $7 / 21$ ). Addition of $1 \mu \mathrm{m} A C h$ ( $g r e e n)$ to the bath solution had no apparent effect on evoked EPSCs.

tions to $52.5 \pm 4.7 \mathrm{pA}$, a $34.6 \%$ increase above baseline (Fig. $3 B$ ). This increase of $S 1$ responses was seen in 26/28 cells studied. This increase in $\mathrm{S} 1$ amplitude also resulted in the paired-pulse ratio (S2/S1) being decreased significantly from $2.54 \pm 0.11$ to $2.17 \pm$ 0.09 (Fig. 3C). A decrease in paired-pulse ratio was observed in $24 / 28$ cells studied. This effect on the paired-pulse ratio was blocked by addition of $100 \mathrm{nM} \mathrm{Dh} \beta \mathrm{E}$ to the bath solution, indicating that the presynaptic nAChRs are likely of $\alpha 4 \beta 2$ stoichiometry (Harvey and Luetje, 1996; Xiao and Kellar, 2004)

The major excitatory glutamatergic projections ascending from IC were stimulated similarly using a bipolar electrode placed on the incoming brachium fibers. Electrical stimulation resulted in either a strong paired-pulse depression (14/21 cells studied; Fig. $3 G$ ) or weak paired-pulse facilitation (7/21 cells studied; Fig. $3 D)$. Cells producing paired-pulse facilitation or depression did not correlate with MGB subdivision. In either case, bath application of ACh had no significant effects on the amplitude of $\mathrm{S} 1$ or paired-pulse ratio (S2/S1; Fig. 3E-F, H,I). Generally cells that showed paired-pulse depression exhibited large, all-or-none evoked EPSCs in response to electrical stimulation.

To verify that excitatory $\mathrm{AC}$ neurons projecting to the MGB express nAChRs, immunohistochemical methods were used on intact slices in which cells that were electrophysiologically studied were filled using Neurobiotin-488 (1\%). We took advantage of known differential expression of VGluTs in the auditory pathway to better address our prediction that $\mathrm{nAChRs} \mathrm{exist} \mathrm{on} \mathrm{descending}$ excitatory terminals. Although VGluT1 is dominant in corticothalamic projections, tectothalamic terminals have been shown to express VGluT2 (Barroso-Chinea et al., 2007; Ito and Oliver, 2010; Hackett et al., 2011, 2016). Figure 4 shows colocalization of the nAChR $\beta 2$ subunit with VGluT1 labeling of presumptive corticothalamic terminals in the area of a distal dendrite of the ventral MGB (vMGB) neuron studied. However, as detailed above in the Materials and Methods, as well as in Moser et al., 2007, particular caution must be used when using antibodybased methods to detect nAChRs because there are commonly issues with subunit specificity. To further support the presence of presynaptic nAChRs on excitatory corticothalamic terminals, we used FISH to detect mRNA for nAChR subunits within AC. Figure 5 shows data from FISH assays providing evidence that VGluT1-positive neurons in the deep layers of AC coexpress the $\alpha 4$ as well as the $\beta 2 n A C h R$ subunit mRNA. Collectively, these data support the contention that $\mathrm{nAChR}$ mRNA is present in $\mathrm{AC}$ excitatory neurons and, once translated and assembled, nAChRs 

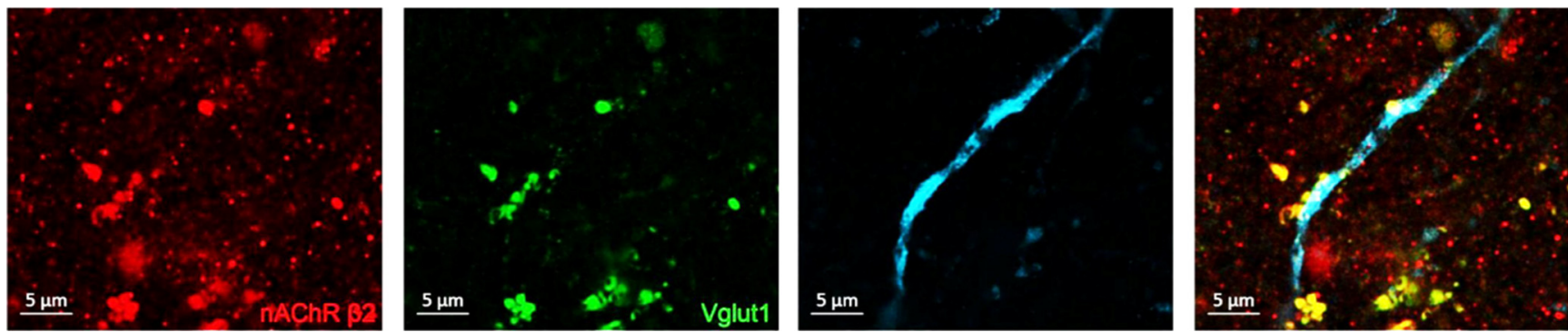

Figure 4. $\quad \mathrm{nAChR} \beta 2$ subunit colocalizes with VGluT1-positive corticothalamic terminals. Shown are representative confocal images of a distal dendrite from a Neurobiotin-labeled MGB neuron (cyan) from an excitatory neuron (VgluT1, green). The nAChR $\beta 2$ subunit (red) labeled corticothalamic terminals apposing the MGB dendrite from a recorded neuron. Scale bar, $5 \mu \mathrm{m}$.

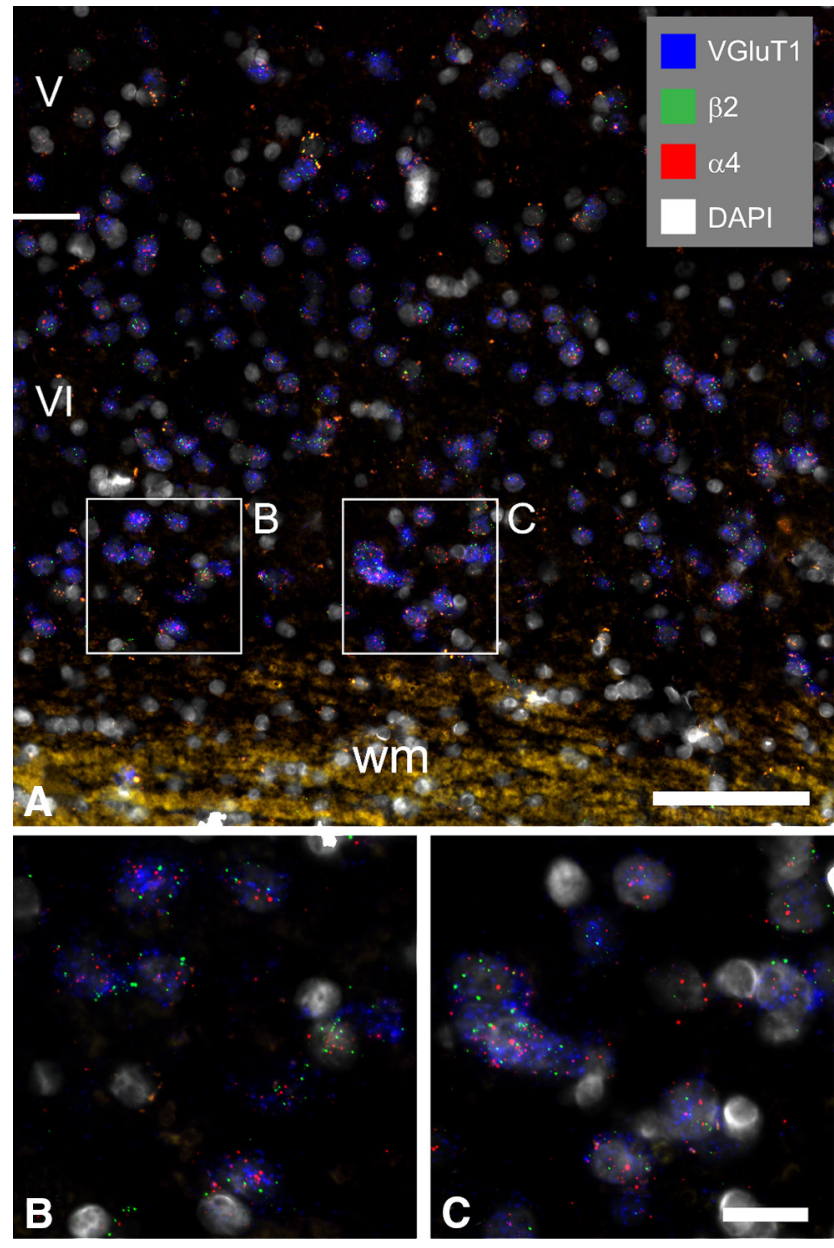

Figure 5. AC VGluT1-positive glutamatergic neurons coexpress $\beta 2$ and $\alpha 4 \mathrm{nAChR}$ subunits. FISH in AC showing VGluT1 (blue), $\alpha 4 \mathrm{nAChR}$ subunit (red), $\beta 2 \mathrm{nAChR}$ subunit (green), and DAPI (blue). A, Low-magnification image of infragranular projection layers LV, LVI, and white matter (wm). Scale bar, $100 \mu \mathrm{m}$. B, C, High-magnification images of VGluT1 projection neurons expressing $\alpha 4$ and $\beta 2 \mathrm{nAChR}$ subunit mRNA (insets from $\boldsymbol{A}$ ). Scale bar, $20 \mu \mathrm{m}$.

are integrated into excitatory corticothalamic terminals within the MGB.

We next examined inhibitory projections from IC and TRN by placing the stimulating electrode on ascending fibers of the brachium of the IC or descending TRN radiations before entering the MGB and blocking excitatory neurotransmission. Inhibitory responses were isolated pharmacologically by bath application of APV $(50 \mu \mathrm{M})$ and DNQX $(20 \mu \mathrm{M})$ to block NMDA and AMPA receptors, respectively. Tectothalamic projections generally exhibited paired-pulse depression, as seen in the exemplar trace in
Figure $6 \mathrm{~A}$. Again, addition of ACh to the bath increased average S1 amplitude elicited by stimulation of the ascending GABAergic IC projection, from $107.0 \pm 10.9 \mathrm{pA}$ at baseline to $125.3 \pm 14.6$ pA, a $17.1 \%$ increase (Fig. $6 B$ ). Similar increases were seen for all 15 cells studied. The paired-pulse ratio was decreased significantly from $0.61 \pm 0.03$ to $0.54 \pm 0.03$ (Fig. $6 C$ ) in $10 / 15$ cells studied. However, stimulation of TRN fibers resulted in pairedpulse depression as shown in the exemplar (Fig. 6D), with no apparent effect of ACh application on either S1 amplitude (Fig. $6 E)$ or the paired-pulse ratio (S2/S1; Fig. $6 F$ ).

To verify that inhibitory IC neurons projecting to MGB express nAChRs, we again used FISH assays to better address our prediction. It is known that the larger IC GABAergic cells project to the MGB and are larger than glutamatergic cells (Ito and Oliver, 2010). Figure 7 shows that larger VGAT-positive neurons in IC express $n A C h R \beta 2 \mathrm{mRNA}$, but infrequently $\alpha 4$. Smaller unlabeled putative glutamatergic neurons appear to be a mixed population, some of which coexpress both $\beta 2$ and $\alpha 4, \beta 2$ only, or neither subunit.

\section{Optogenetic stimulation of corticothalamic and tectothalamic MGB inputs}

Using electrical stimulation, there is a chance of stimulating fibers of passage into MGB, which may include projections from regions other than the IC or AC. To verify the presence of presynaptic nAChRs on the excitatory corticothalamic projections and inhibitory tectothalamic projections, an optogenetic approach was used. For this, 0.5-1 $\mu \mathrm{l}$ of AAV-CaMKIIa-hChR2(H134R)eYFP was placed into either the central nucleus of IC or L5/L6 of AC. Although mCaMKIIa promoters are typically used to drive expression in only excitatory neurons, use of AAV2 can transduce both excitatory and inhibitory neuronal populations efficiently (Nathanson et al., 2009). To verify that IC inhibitory terminals can express ChR2 under the control of the CaMKIIa promoter, IC terminals in MGB were imaged. Figure 8 shows GAD immunostaining colocalizing with YFP labeled IC projection terminals. A $21 \mathrm{~d}$ postmicroinjection period allowed for expression of hChR2 and eYFP in MGB projection terminals. Modified thalamocortical slices were made to preserve as much connectivity between IC-MGB or AC-MGB as possible (Llano et al., 2014). Coexpression of eYFP in the viral vector allowed visualization of the optogenetically labeled projection descending from AC to MGB and the ascending projection from IC to MGB (Fig. 9A,D). Once an MGB neuron was patched successfully, a $470 \mathrm{~nm}$ LED was used to evoke synaptic release to emulate the electrical paired-pulse paradigm. Supporting what was seen with electrical stimulation, optical stimulation of axons from L5 and/or L6 of pyramidal cells from auditory cortex elicited significant increases in $\mathrm{S} 1$ amplitude from $48.3 \pm 6.0 \mathrm{pA}$ to $69.9 \pm 12.8 \mathrm{pA}$ with $\mathrm{ACh}$ application, whereas the paired-pulse ratio showed a significant 
A Inhibitory Tectothalamic Input

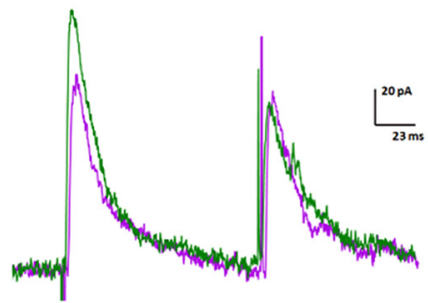

D Inhibitory Thalamic Reticular Nucleus Input

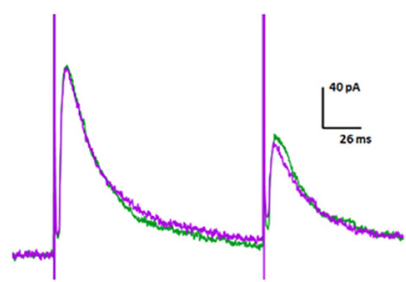

B

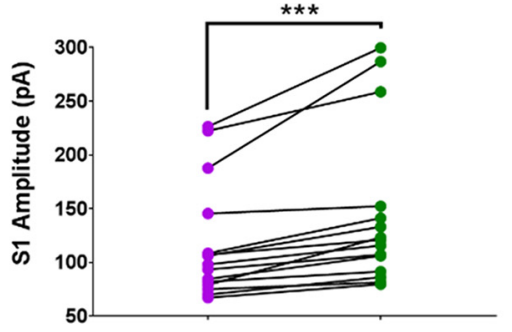

E

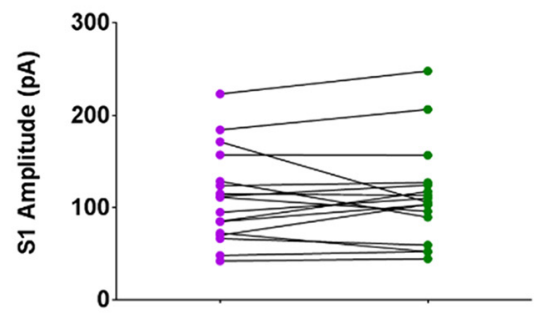

C

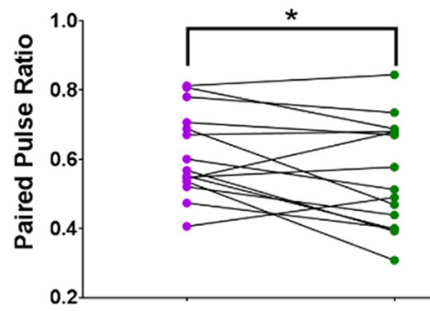

$\mathbf{F}$

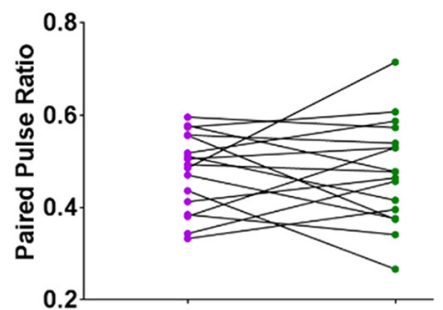

Figure 6. Activation of $n A C h R$ enhances $G A B A$ release at tectothalamic terminals, but has no effect at thalamic reticular nucleus terminals. Inhibitory currents elicited from electrical stimulation of the descending fibers from TRN or ascending IC fibers were recorded from MGB neurons in the presence of atropine (20 $\mu \mathrm{M})$, APV (50 $\mu \mathrm{M})$, and DNQX (20 $\mu \mathrm{M})$. $\boldsymbol{A}-\boldsymbol{C}$, Tectothalamic input. Traces show IPSCs evoked from electrical stimulation of IC fibers as recorded from a MGB neuron ( $\boldsymbol{A})$. Connected dot plots compare 51 amplitude $(\mathrm{pA} ; \boldsymbol{B})$ and paired-pulse ratios $(\boldsymbol{C})$. Bath application of $1 \mu \mathrm{M}$ ACh caused an increase in the amplitude of $S 1$ and decreased the paired-pulse ratio. Paired $t$ tests were used for all comparisons $(n=15) .{ }^{* * *} p<0.001,{ }^{*} p<0.05$. D-F, Thalamic reticular nucleus input. Traces show IPSCs evoked from electrical stimulation of TRN fibers as recorded from an MGB neuron. Addition of $1 \mu \mathrm{m}$ ACh (green) to the bath solution had no apparent effect on evoked IPSCs as seen in the exemplar (D) and the connected dot plot comparisons of $S 1$ amplitude $(\mathrm{pA} ; \boldsymbol{E})$ and paired-pulse ratios $(\boldsymbol{F})(n=17)$.

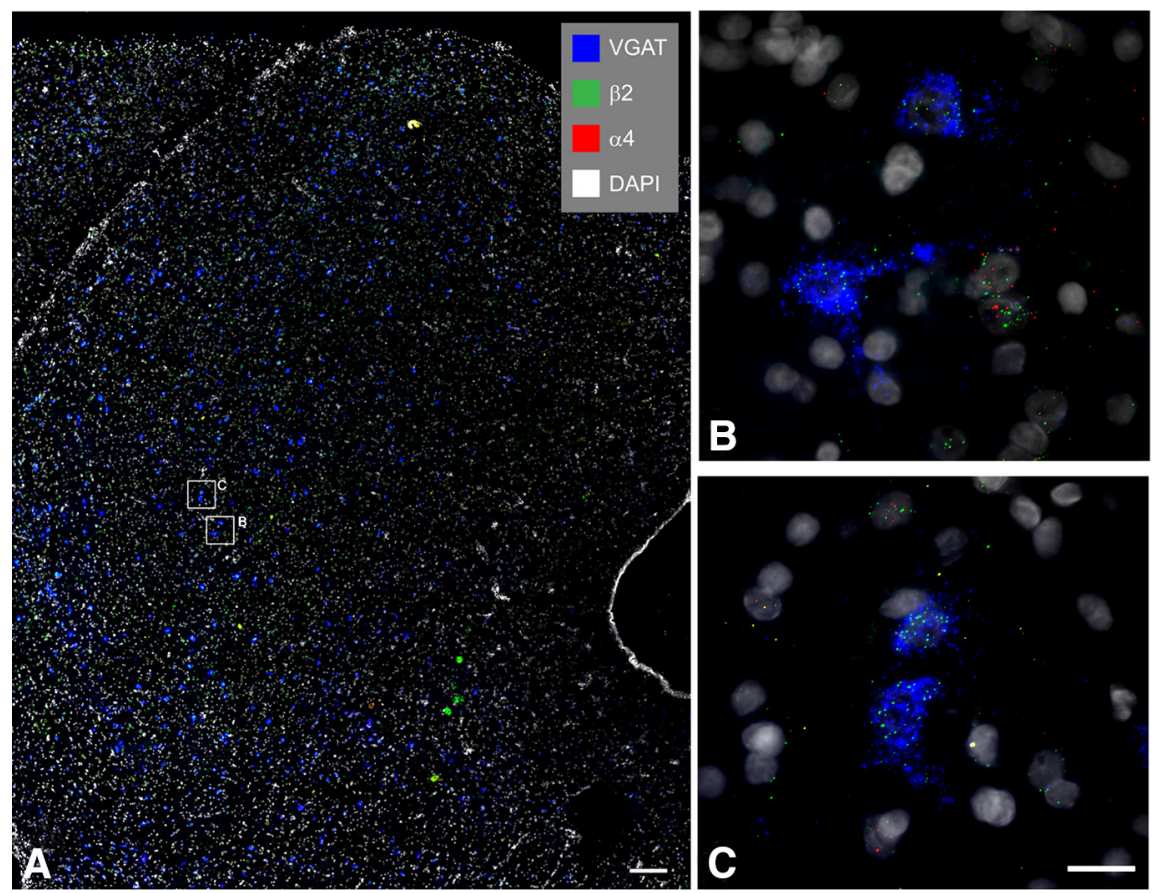

Figure 7. IC VGAT-positive GABAergic neurons express $\beta 2$, but not $\alpha 4$, nAChR subunits, whereas some VGAT-negative cells coexpress both. FISH in the IC shows VGAT (blue), $\alpha 4 \mathrm{nAChR}$ subunit (red), $\beta 2 \mathrm{nAChR}$ subunit (green), and DAPI (white). $A$, Low-magnification image montage of the IC. Scale bar, $250 \mu \mathrm{m}$. $B, C$, High-magnification images of insets from $\boldsymbol{A}$ showing blue VGAT-labeled large inhibitory, putative projection neurons expressing $\beta 2 \mathrm{nAChR}$ subunit mRNA and unlabeled putative glutamatergic neurons expressing $\alpha 4$ and $\beta 2 \mathrm{nAChR}$ subunit mRNAs. Scale bar, $20 \mu \mathrm{m}$.

decrease from $1.51 \pm 0.21$ to $1.02 \pm 0.09$ (Fig. 9C). Optical stimulation of inhibitory tectothalamic projections also mirrored findings with electrical stimulation, showing a significant increase in S1 amplitude from $155.03 \pm 20.64 \mathrm{pA}$ to $180.26 \pm 21.25$
$\mathrm{pA}$, whereas the paired-pulse ratio showed a significant decrease from $0.65 \pm 0.06$ to $0.57 \pm 0.06$ (Fig. 9F).

\section{Impact of aging on excitatory corticothalamic and inhibitory tectothalamic MGB inputs}

The impact of aging on the MGB was examined on inputs showing evidence of presynaptic nAChR action in the young adult: excitatory corticothalamic projections and inhibitory tectothalamic projections. No statistically significant differences in RMP or input resistance were found between the 93 MGB neurons recorded from young adult (4-6 months) rats and the 67 neurons recorded from aged (28-32 months) animals (Table 2). Excitatory corticothalamic projections showed pairedpulse responses in aged MGB neurons that were similar to recordings from young adult MGB neurons with ACh application increasing S1 amplitude with a nonsignificant decrease in the paired-pulse ratio (Fig. 10A). However, ACh effects were diminished compared with what was seen in the young adult MGB circuitry. Aged corticothalamic excitatory projections show significant $\mathrm{S} 1$ increases in amplitude from $39.3 \pm 3.2 \mathrm{pA}$ to $46.5 \pm 5.3 \mathrm{pA}$, whereas the paired-pulse ratio showed a nonsignificant $(p=0.09)$ decrease from $2.13 \pm 0.08$ to $2.01 \pm 0.09$. When normalized and compared with the S1 data from young adult MGB neurons, there was a significant decrease in the mag- 

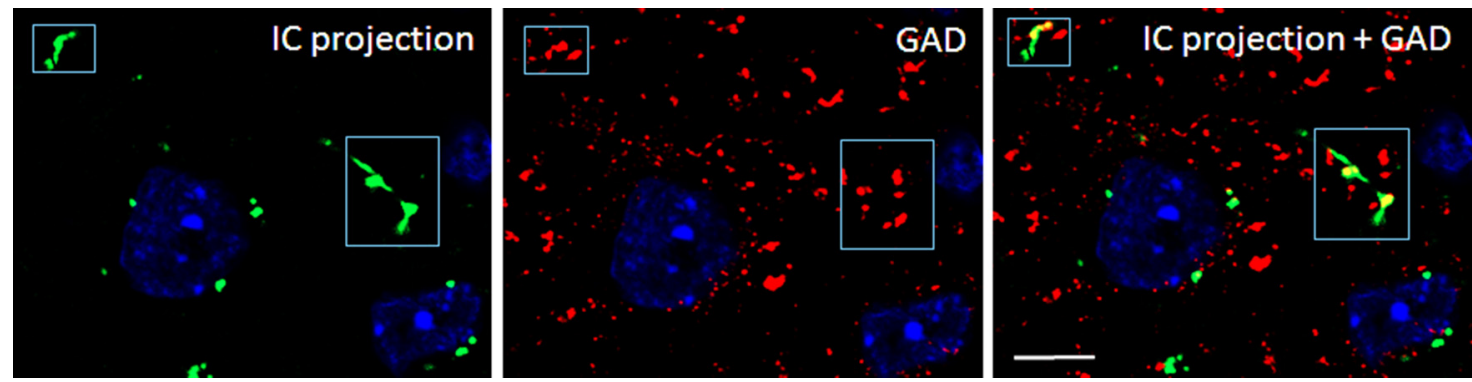

Figure 8. IC inhibitory terminals in MGB expressing YFP under the control of the CaMKIlla promoter. AAV-CaMKIla-hChR2(H134R)-eYFP was injected into IC. IHC in MGBshows labeled IC terminals (green), GAD (red), and DAPI (blue). IC injection appears as punctate green label at the level of MGB. GAD staining is shown to colocalize with some of the labeled IC terminals (boxed region). Scale bar, $10 \mu \mathrm{m}$.

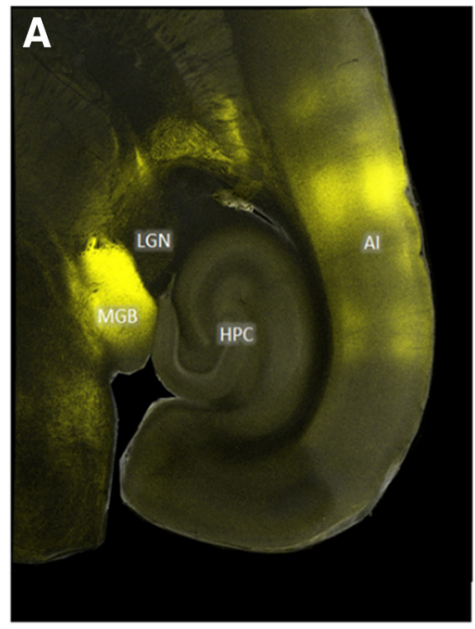

B

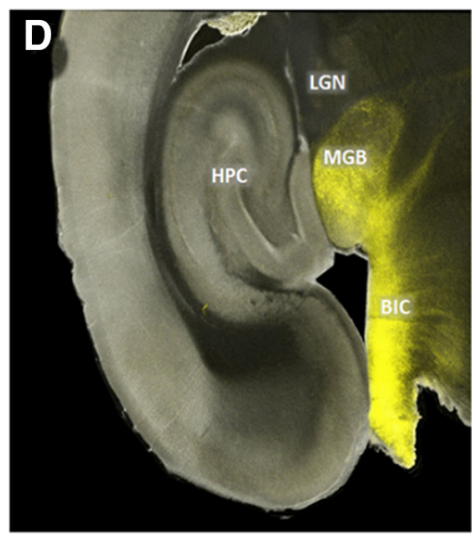

$\mathbf{E}$

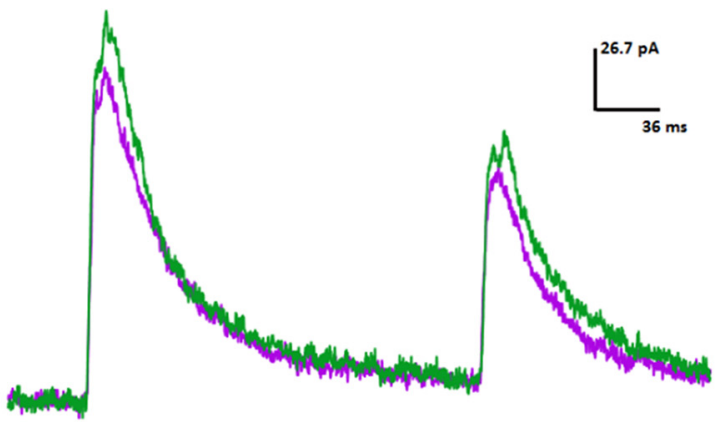

C
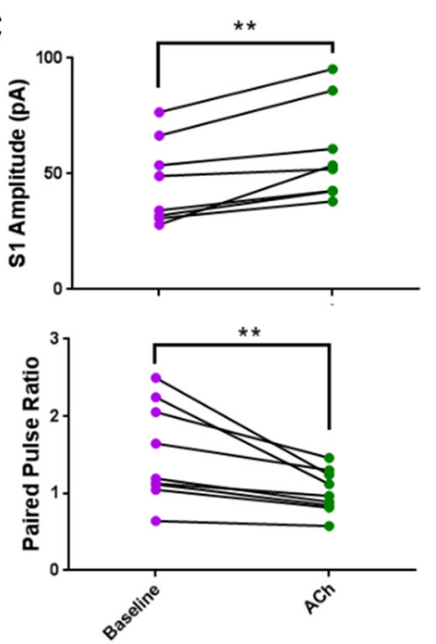

$\mathbf{F}$

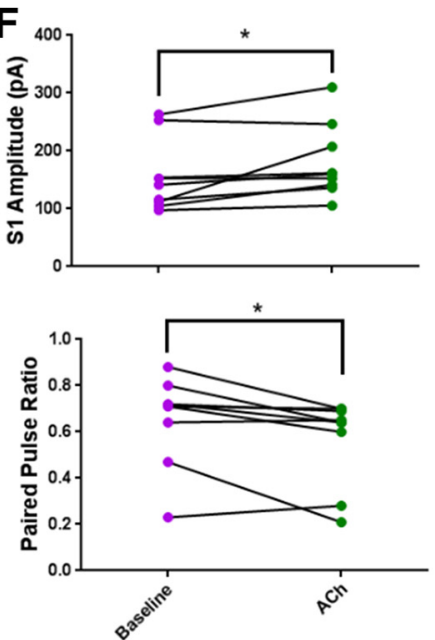

Figure 9. Activation of nAChRs at optogenetically stimulated presynaptic excitatory corticothalamic and inhibitory tectothalamic inputs. $A$, Confocal image showing a wide-field view of eYFP-labeled (yellow) excitatory corticothalamic projection that express the hChR2 virus. $\boldsymbol{B}, \boldsymbol{C}$, Exemplar $(\boldsymbol{B})$ and connected dot plots $(\boldsymbol{C})$ showing change in $\mathrm{S} 1$ amplitude (pA) and paired-pulse ratios induced with bath-applied ACh. D, Confocal image showing the eYFP-labeled (yellow) inhibitory tectothalamic projection (BIC), which expresses the hChR2 virus. $\boldsymbol{E}, \boldsymbol{F}$, Exemplar $(\boldsymbol{E})$ and connected dot plots $(\boldsymbol{F})$ showing the change in $\mathrm{S1}$ amplitude $(\mathrm{pA})$ and paired-pulse ratios induced with bath applied $\mathrm{ACh}\left(n=9\right.$ for both groups). Paired $t$ tests were used for all comparisons; ${ }^{*} p<0.05$, ${ }^{* *} p<0.01$.

nitude of nAChR-mediated presynaptic responses. The S1 AChmediated enhancement decreased from $34.5 \%$ in young adult MGB neurons to $18.4 \%$ in recordings from aged MGB neurons (Fig. 10A).

Paired-pulse responses from aged MGB neurons revealed that inhibitory tectothalamic projections also showed significant nAChR-
Table 2. Membrane properties of young adult and aged MGB neurons

\begin{tabular}{lll}
\hline & $\mathrm{RMP}(\mathrm{mV})$ & $R_{\mathrm{m}}(\mathrm{M} \Omega)$ \\
\hline Young adult $(4-6 \mathrm{mo})$ & $-69.76 \pm 0.59$ & $169.81 \pm 7.13$ \\
Aged $(28-32 \mathrm{mo})$ & $-69.37 \pm 0.67$ & $189.59 \pm 11.49$
\end{tabular}

$n=94$ young adult and 67 aged MGB neurons.

RMP, Resting membrane potential; $R_{\mathrm{m}}$, membrane resistance. 


\section{A Aged - Excitatory Corticothalamic Input}
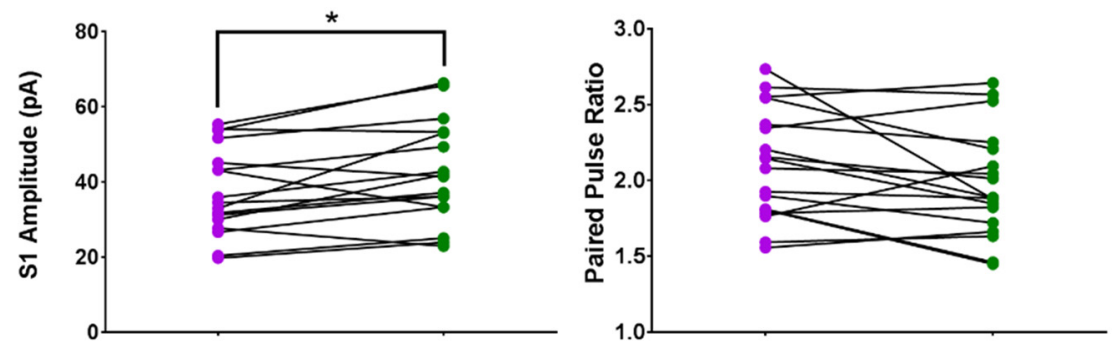

\section{B Aged - Inhibitory Tectothalamic Input}
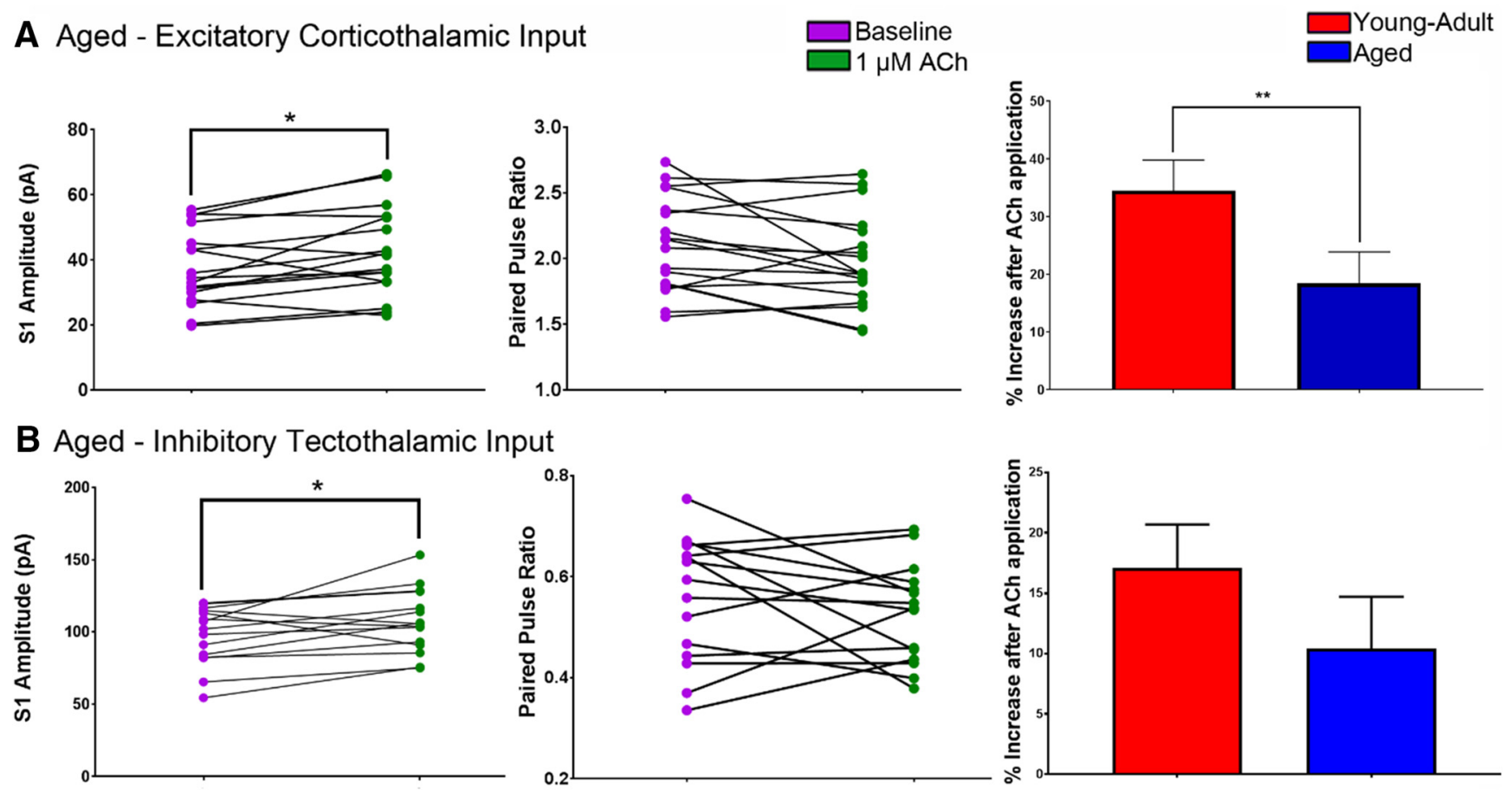

Figure 10. Impact of aging on presynaptic nAChRs at excitatory corticothalamic and inhibitory tectothalamic inputs. Currents were elicited from aged ( $28-32$ months old) rats using electrical stimulation at the descending fibers from AC or ascending IC fibers. Inhibition or excitation was blocked pharmacologically as described previously. $A$, Excitatory corticothalamic input in aged rats. Connected dot plots show the change in $\mathrm{S1}$ amplitude ( $\mathrm{pA}$; left) and paired-pulse ratios (middle) induced by nAChR activation in aged FBN rats. $n=18$. Total increase in evoked current in both young adult and aged rats was compared with the peak amplitude of that before addition of $1 \mathrm{~mm} \mathrm{ACh} \mathrm{to} \mathrm{the} \mathrm{bath} \mathrm{solution.} \mathrm{The} \mathrm{capacity} \mathrm{of} \mathrm{ACh} \mathrm{to} \mathrm{increase} \mathrm{glutamatergic} \mathrm{response} \mathrm{was} \mathrm{significantly} \mathrm{greater}$ in the young adult neurons compared with the aged neurons ( $34.5 \%$ increase in young vs $18.4 \%$ increase in aged; right; $n=28$ young, 18 aged). Paired $t$ tests were used for comparisons before and after drug application. Unpaired $t$ tests were used for young/aged comparisons. ${ }^{* *} p<0.01,{ }^{*} p<0.05$. $\boldsymbol{B}$, Inhibitory tectothalamic terminals in aged rats. Connected dot plots show the change in $\mathrm{S} 1$ amplitude (pA; left) and paired-pulse ratio (middle) induced by nAChR activation in aged FBN rats $(n=15)$. The capacity of ACh to increase GABAergic response was not significantly different between young adult and aged groups ( $22.38 \%$ increase in young vs $10.44 \%$ increase in aged; right; $n=24$ young, 15 aged).

mediated increases in S1 amplitude $(97.49 \pm 5.21 \mathrm{pA}$ to $107.67 \pm$ $5.7 \mathrm{pA} ; p<0.05)$, whereas the paired-pulse ratio nonsignificantly decreased from $0.56 \pm 0.03$ to $0.53 \pm 0.03$ ( $p=0.31$; Fig. $10 B)$. There is a trend in which the S1 ACh-mediated enhancement decreased from $17.1 \%$ in young adult MGB neurons to $10.4 \%$ in recordings from aged MGB neurons ( $p=0.55$; Fig. 10B). These data point to a general loss of efficacy of presynaptic nicotinic cholinergic signaling in aging.

\section{Discussion}

Findings from the present studies describe the location of presynaptic nAChRs on the four primary inputs to MGB. The circuitry is summarized in Figure 11, which shows the major inputs to MGB, the neurotransmitter systems involved with each, postsynaptic nAChRs that have been thoroughly studied in Sottile et al. (2017), and proposed locations of presynaptic nAChRs. In addition, these studies find an age-related decrease in the ability of ACh to modulate presynaptic nAChR function.

\section{Relative effects of ACh on spontaneous EPSPs and IPSPs}

The frequency of spontaneous EPSCs and IPSCs were enhanced when ACh was applied in the vicinity of MGB neurons. The greater increase in EPSCs compared with IPSCs (Fig. 1) likely reflects the existence of presynaptic nAChRs on the expansive numbers of glutamatergic fibers descending from AC as detailed by Winer and Schreiner (2005). Rat tectothalamic projections are $\sim 75 \%$ glutamatergic to $25 \%$ GABAergic (Winer et al., 1996; Ito and Oliver, 2012). The larger numbers of corticothalamic glutamatergic terminals within the MGB relative to tectothalamic
GABAergic terminals may explain the differential ACh evoked increases in spontaneous EPSCs relative to the ACh-evoked IPSC increases detailed above.

\section{Effects of ACh on descending excitatory projections from AC}

We show here that presynaptic nAChRs exist on descending glutamatergic projections from AC (Figs. 3, 4, 5). Primary AC and vMGB are broadly reciprocally connected, with L6 corticothalamic terminals ending on distal, small-caliber, higher-order MGB dendrites (Bartlett et al., 2000; Winer et al., 2001; Smith et al., 2007; Llano and Sherman, 2008). Corticothalamic pathways generate dynamic, context-dependent changes in the response properties of MGB neurons, forming a signaling loop (Bartlett, 2013). Corticothalamic projections can alter the strength and shape of MGB receptive fields acting to enhance transmission of sensory information (Edeline and Weinberger, 1991; Andolina et al., 2013; Guo et al., 2017). Previous studies have shown a feedback-dependent shift in the tuning of MGB neurons toward the preferred frequency of active feedback neurons (Suga and Ma, 2003; Wu and Yan, 2007; Zhang and Yan, 2008). There is also evidence that the descending pathway may play a critical role in detection of harmonicity and thus auditory scene analysis (Homma et al., 2017). In support of our electrophysiologic findings, we show that AC L6 projection neurons have high levels of $\alpha 4$ and $\beta 2$ nAChR subunit mRNA (Fig. 4). nAChR-mediated potentiation of signal transmission from AC to MGB may increase the gain in response to novel auditory stimuli while altering patterns of thalamocortical activity. 


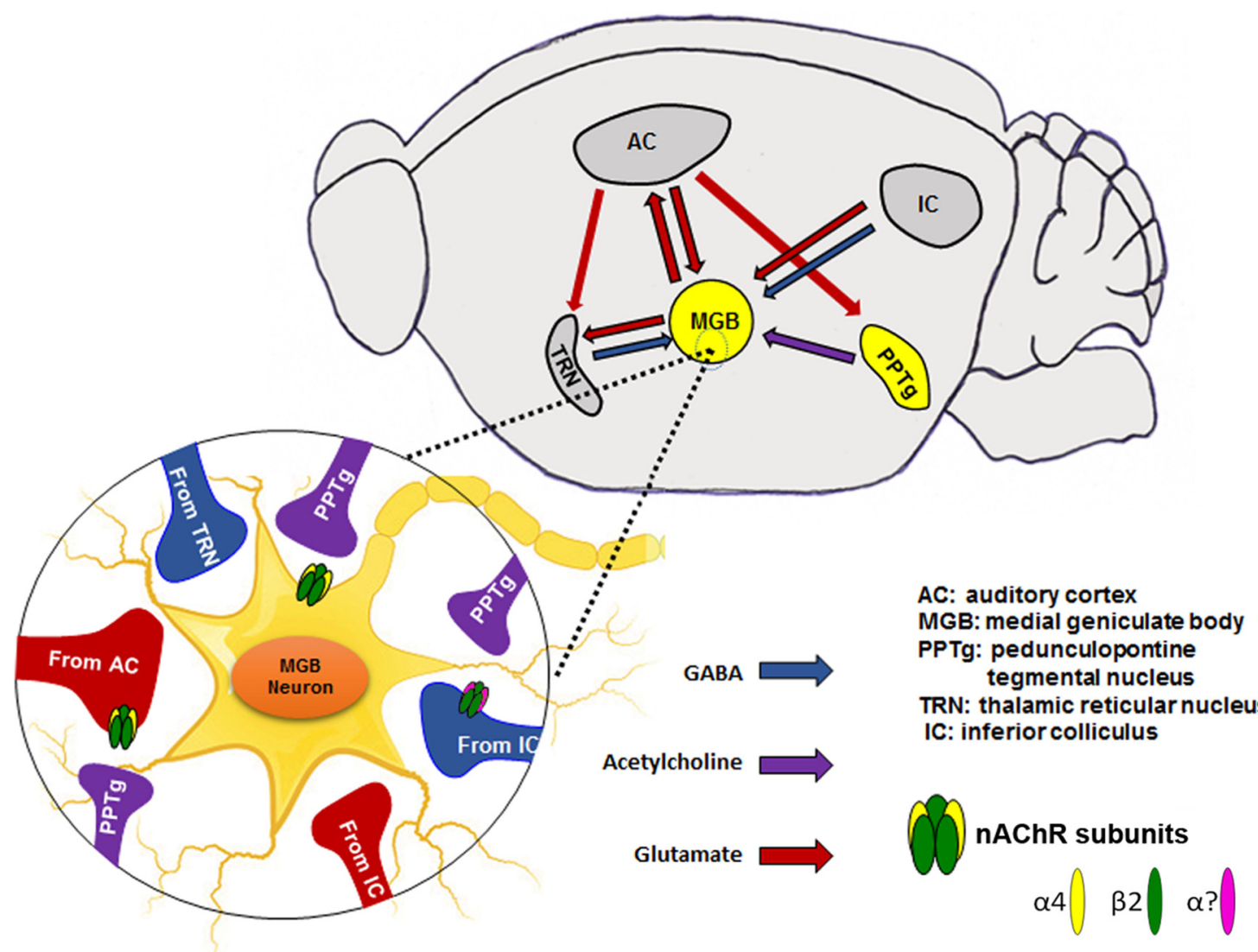

Figure 11. Major inputs to the MGB and their neurotransmitters. The responses of MGB neurons are dictated by excitatory and inhibitory sensory inputs from IC, excitatory input from $A C$, and inhibitory input from TRN. ACh released from PPTg may then activate nAChRs within the MGB circuitry. Inset shows proposed nAChR sites for cholinergic modulation/activation of MGB neurons. Shown are postsynaptic nAChRs on MGB neurons (Sottile et al., 2017) and presynaptic nAChRs on excitatory corticothalamic input, both of which are likely to be $\alpha 4 \beta 2 \mathrm{nAChRs}$, whereas presynaptic nAChRs on inhibitory tectothalamic input are $\beta 2$-containing nAChRs with a different $\alpha$ subunit.

Effects of ACh on ascending inhibitory projections from IC We show here that activation of nAChRs potentiates evoked responses from GABAergic terminals originating in IC (Fig. 6). These data are supported by FISH studies showing that large IC GABAergic neurons express $\beta 2 \mathrm{nAChR}$ subunit mRNA (Fig. 7). The $\alpha 4 \mathrm{nAChR}$ subunit mRNA was detected infrequently in these neurons and the nature of the $\mathrm{nAChR} \alpha$ subunit associated with these GABAergic projection neurons remains to be determined. Tectothalamic GABAergic projection neurons are large neurons found in all IC subdivisions that may project to any subdivision of MGB, although not all MGB cells receive inhibitory tectothalamic input (Bartlett and Smith, 1999; Ito and Oliver, 2012). GABAergic IC projection neurons form short-latency, monosynaptic inputs to MGB neurons and are considered critical for temporal processing of auditory signals (Peruzzi et al., 1997; Venkataraman and Bartlett, 2013). Either excitatory or inhibitory input may reach MGB first, suggesting that the GABA released may influence onset and duration of neuronal responses to sound (Lennartz and Weinberger, 1992; Abrams et al., 2011). nAChR facilitation of tectothalamic GABAergic projections may serve to improve the signal-to-noise ratio, heightening signal contrast while improving signal transmission during periods of attention.

Impact of ACh on other ascending and descending MGB inputs

Unlike the cholinergic potentiation evident on excitatory corticothalamic and inhibitory tectothalamic terminals, little or no evidence was found for presynaptic activation of nAChRs on inhibitory projections from TRN to MGB. This was unexpected because TRN is thought to underlie the selection of relevant sensory signals and the suppression of distractors in the sensory environment (Guillery et al., 1998; Pinault, 2004; Zikopoulos and Barbas, 2007). The transition from an oscillatory to a relay mode of operation in thalamic neurons is controlled in part by cholinergic modulation of TRN neurons (Hu et al., 1989). TRN receives cholinergic input from nucleus basalis and short trains of cholinergic synaptic input have been shown to entrain TRN neuronal activity powerfully (McCormick and Bal, 1997; Sun et al., 2013). Together with our findings, we therefore speculate that the outputs of TRN neurons are primarily modulated by direct cortical attentional networks at the level of their somata and dendrites, not their presynaptic terminals in the MGB.

Excitatory IC projections to MGB show variable synaptic properties. Consistent with findings in Bartlett and Smith (2002), the present study finds two classes of excitatory tectothalamic inputs on to MGB neurons: synapses exhibiting paired-pulse depression and those exhibiting weak paired-pulse facilitation, with the majority showing paired-pulse depression. Conversely, a study by Lee and Sherman (2010) found that lateral IC (ICl) projections to $\mathrm{dMGB}$ showed primarily paired-pulse facilitation, whereas central IC (ICc) projections to vMGB showed pairedpulse depression. The present study did not stimulate ICl versus ICc fibers selectively, which may explain the lower level of pairedpulse facilitation observed compared with Lee and Sherman (2010). Anatomically, two types of glutamatergic neurons in IC 
can be delineated by size. Glutamatergic IC neurons with smaller terminals coinnervate tufted or stellate MGB neurons along with large GABAergic neurons, whereas other tufted neurons are innervated by glutamatergic neurons with larger terminals and do not receive GABAergic inputs from IC (Ito and Oliver, 2012). In the present study, MGB neurons exhibiting paired-pulse depression did not exhibit consistent potentiation by ACh; however, there were some neurons in both the dorsal and ventral subdivisions that were modulated by ACh, leading us to believe that excitatory IC inputs exhibiting paired-pulse depression may be a mixed population. FISH assays appear to support a diverse expression of $\mathrm{nAChR} \beta 2$ - and $\alpha 4$-subunit mRNA in a subset of glutamatergic IC neurons (Fig. 7). This diversity within IC is further supported by findings from the present study and prior mRNA and receptor binding studies showing differences between ICc and nonlemniscal IC (Wada et al., 1989). With multiple glutamatergic inputs and an ascending GABAergic input from IC, tectothalamic auditory information is dependent on how and when these different inputs are activated. It is likely that the unique convergence of tectothalamic inputs into MGB has an equally complex distribution of presynaptic nAChRs for selective enhancement in conditions of increased attentional demand.

When a behaviorally relevant signal activates both PPTg and basal forebrain cholinergic circuits, there is simultaneous activation of tectothalamic and TRN inhibitory projections to the MGB, activating tonic $\mathrm{GABA}_{\mathrm{A}}$ Rs to prime T-type Ca channels (Sarter and Bruno, 2000; Cope et al., 2005; Richardson et al., 2011). Simultaneous cholinergic activation of the descending projection from AC may drive relevant MGB neurons selectively into gamma oscillations (Llinas et al., 2002; Llinas and Steriade, 2006). This selective cholinergic impact is also seen in auditory cortex, where nucleus basalis stimulation enhances excitatory events and decreases inhibitory events, transiently desynchronizing cortical activity and altering the excitatory-inhibitory balance for seconds to minutes (Froemke et al., 2007). Thus, potentiating neurotransmitter release from excitatory corticothalamic inputs and inhibitory tectothalamic terminals could allow for improved temporal processing and integration of the ascending sensory stream with cortical library information to optimize input based on previous experiences and knowledge. This combination of enhancements initiated by cholinergic streams activated in periods of sustained attention may lead to a more refined perception of a novel or unclear auditory stimulus. It is through these mechanisms that we believe MGB can improve the detection and recognition of a given auditory stimulus. Schofield et al. (2011) and Metherate et al. (2012) provide general overviews of how cholinergic projections from PPTg and basal forebrain affect brainstem and cortical auditory structures.

\section{Attentional needs increase ACh release from PMT that could alter the nature of the acoustic message: a process diminished by aging}

Aging attenuated nAChR-mediated presynaptic enhancement of excitatory corticothalamic and inhibitory tectothalamic neurotransmitter release significantly. This is complemented by the recent findings of Sottile et al. (2017) showing an age-related loss of $\mathrm{nAChR}$ postsynaptic efficacy. In that study, the investigators specifically describe an age-related loss in the ability of ACh to depolarize MGB neurons likely based on a loss of heteromeric nAChRs. In addition, Sottile et al. (2017) proposed a subunit change in the makeup of the nAChRs, with higher numbers of lower affinity $\beta 4$-containing $\mathrm{nAChRs}$ constructs relative to $\beta 2$ containing nAChRs.
Nicotinic signaling is critical to many aspects of cognition, including maintaining attention. Nicotinic actions at the neuronal level have been shown to affect network gamma oscillations that are strongly correlated with sensorimotor gating and cognitive activity (Mansvelder et al., 2006). Stimulation of PPTg induces thalamocortical neurons affecting gamma oscillations, increasing discharge rates and bursting in the MGB (Steriade and McCarley, 1990), an action likely mediated by presynaptic nAChRs (Millar and Gotti, 2009). This cholinergic action mediated through nAChRs in MGB likely plays a key role in assigning salience to acoustic stimuli.

Age-related cholinergic dysfunction at the level of MGB may affect speech understanding negatively by impeding one's ability to process sounds, sustain attention, and/or bind an auditory stimulus appropriately to form an accurate perception of one's environment. It is our hope that improved understanding of the age-related changes that occur in the auditory system will lead to further information on how sensory systems are altered over a life time and provide us with novel targets for agents that may compensate for altered nicotinic input.

\section{References}

Abrams DA, Nicol T, Zecker S, Kraus N (2011) A possible role for a paralemniscal auditory pathway in the coding of slow temporal information. Hearing Res 272:125-134. CrossRef Medline

Alain C, McDonald KL, Ostroff JM, Schneider B (2004) Aging: a switch from automatic to controlled processing of sounds?. Psychol Aging 19: 125-133. CrossRef Medline

Andolina IM, Jones HE, Sillito AM (2013) Effects of cortical feedback on the spatial properties of relay cells in the lateral geniculate nucleus. J Neurophysiol 109:889-899. CrossRef Medline

Aubert I, Araujo DM, Cécyre D, Robitaille Y, Gauthier S, Quirion R (1992) Comparative alterations of nicotinic and muscarinic binding sites in Alzheimer's and Parkinson's diseases. J Neurochem 58:529-541. CrossRef Medline

Bajo VM, Rouiller EM, Welker E, Clarke S, Villa AE, de Ribaupierre Y, de Ribaupierre F (1995) Morphology and spatial distribution of corticothalamic terminals originating from the cat auditory cortex. Hear Res 83:161-174. CrossRef Medline

Barroso-Chinea P, Castle M, Aymerich MS, Pérez-Manso M, Erro E, Tuñon T, Lanciego JL (2007) Expression of the mRNAs encoding for the vesicular glutamate transporters 1 and 2 in the rat thalamus. J Comp Neurol 501:703-715. CrossRef Medline

Bartlett EL (2013) The organization and physiology of the auditory thalamus and its role in processing acoustic features important for speech perception. Brain Lang 126:29-48. CrossRef Medline

Bartlett EL, Smith PH (2002) Effects of paired-pulse and repetitive stimulation on neurons in the rat medial geniculate body. Neuroscience 113:957974. CrossRef Medline

Bartlett EL, Wang X (2011) Correlation of neural response properties with auditory thalamus subdivisions in the awake marmoset. J Neurophysiol 105:2647-2667. CrossRef Medline

Bartlett EL, Stark JM, Guillery RW, Smith PH (2000) Comparison of the fine structure of cortical and collicular terminals in the rat medial geniculate body. Neuroscience 100:811-828. CrossRef Medline

Bartlett EL, Smith PH (1999) Anatomic, intrinsic, and synaptic properties of dorsal and ventral division neurons in rat medial geniculate body. J Neurophysiol 81:1999-2016. Medline

Bartus RT, Dean RL 3rd, Beer B, Lippa AS (1982) The cholinergic hypothesis of geriatric memory dysfunction. Science 217:408-414. CrossRef Medline

Bertoli S, Heimberg S, Smurzynski J, Probst R (2001) Mismatch negativity and psychoacoustic measures of gap detection in normally hearing subjects. Psychophysiology 38:334-342. CrossRef Medline

Bidelman GM, Villafuerte JW, Moreno S, Alain C (2014) Age-related changes in the subcortical-cortical encoding and categorical perception of speech. Neurobiol Aging 35:2526-2540. CrossRef Medline

Boucetta S, Cissé Y, Mainville L, Morales M, Jones BE (2014) Discharge profiles across the sleep-waking cycle of identified cholinergic, GABAer- 
gic, and glutamatergic neurons in the pontomesencephalic tegmentum of the rat. J Neurosci 34:4708-4727. CrossRef Medline

Cardin JA, Carlén M, Meletis K, Knoblich U, Zhang F, Deisseroth K, Tsai LH, Moore CI (2010) Targeted optogenetic stimulation and recording of neurons in vivo using cell-type-specific expression of Channelrhodopsin-2. Nat Protoc 5:247-254. CrossRef Medline

Cope DW, Hughes SW, Crunelli V (2005) GABAA receptor-mediated tonic inhibition in thalamic neurons. J Neurosci 25:11553-11563. CrossRef Medline

Cotillon-Williams N, Huetz C, Hennevin E, Edeline JM (2008) Tonotopic control of auditory thalamus frequency tuning by reticular thalamic neurons. J Neurophysiol 99:1137-1151. CrossRef Medline

Cox BC, Marritt AM, Perry DC, Kellar KJ (2008) Transport of multiple nicotinic acetylcholine receptors in the rat optic nerve: high densities of receptors containing $\alpha 6$ and $\beta 3$ subunits. J Neurochem 105:1924-1938. CrossRef Medline

Dani JA, Bertrand D (2007) Nicotinic acetylcholine receptors and nicotinic cholinergic mechanisms of the central nervous system. Annu Rev Pharmacol Toxicol 47:699-729. CrossRef Medline

Edeline JM, Weinberger NM (1991) Thalamic short-term plasticity in the auditory system: Associative retuning of receptive fields in the ventral medial geniculate body. Behav Neurosci 105:618-639. CrossRef Medline

Froemke RC, Merzenich MM, Schreiner CE (2007) A synaptic memory trace for cortical receptive field plasticity. Nature 450:425-429. CrossRef Medline

Guillery RW, Feig SL, Lozsádi DA (1998) Paying attention to the thalamic reticular nucleus. Trends Neurosci 21:28-32. CrossRef Medline

Guo W, Clause AR, Barth-Maron A, Polley DB (2017) A corticothalamic circuit for dynamic switching between feature detection and discrimination. Neuron 95:180-194.e5. CrossRef Medline

Hackett TA, Takahata T, Balaram P (2011) VGLUT1 and VGLUT2 mRNA expression in the primate auditory pathway. Hear Res 274:129-141. CrossRef Medline

Hackett TA, Clause AR, Takahata T, Hackett NJ, Polley DB (2016) Differential maturation of vesicular glutamate and GABA transporter expression in the mouse auditory forebrain during the first weeks of hearing. Brain Struct Funct 221:2619-2673. CrossRef Medline

Harris KC, Wilson S, Eckert MA, Dubno JR (2012) Human evoked cortical activity to silent gaps in noise: effects of age, attention, and cortical processing speed. Ear and hearing 33:330-339. CrossRef Medline

Harvey SC, Luetje CW (1996) Determinants of competitive antagonist sensitivity on neuronal nicotinic receptor $\beta$ subunits. J Neurosci 16:37983806. Medline

He J (2003) Corticofugal modulation of the auditory thalamus. Exp Brain Res 153:579-590. CrossRef Medline

Homma NY, Happel MFK, Nodal FR, Ohl FW, King AJ, Bajo VM (2017) A role for auditory corticothalamic feedback in the perception of complex sounds. J Neurosci 37:6149-6161. CrossRef Medline

Hu B, Steriade M, Deschênes M (1989) The effects of brainstem peribrachial stimulation on perigeniculate neurons: the blockage of spindle waves. Neuroscience 31:1-12. CrossRef Medline

Humes LE, Dubno JR, Gordon-Salant S, Lister JJ, Cacace AT, Cruickshanks KJ, Gates GA, Wilson RH, Wingfield A (2012) Central presbycusis: a review and evaluation of the evidence. J Am Acad Audiol 23:635-666. CrossRef Medline

Ito T, Oliver DL (2012) The basic circuit of the IC: tectothalamic neurons with different patterns of synaptic organization send different messages to the thalamus. Front Neural Circuits 6:48. Medline

Ito T, Oliver DL (2010) Origins of glutamatergic terminals in the inferior colliculus identified by retrograde transport and expression ofVGLUT1 and VGLUT2 genes. Front Neuroanat 4:135. CrossRef Medline

Jensen AA, Frølund B, Liljefors T, Krogsgaard-Larsen P (2005) Neuronal nicotinic acetylcholine receptors: structural revelations, target identifications, and therapeutic inspirations. J Med Chem 48:4705-4745. CrossRef Medline

Jones BE (1991) The role of noradrenergic locus coeruleus neurons and neighboring cholinergic neurons of the pontomesencephalic tegmentum in sleep-wake states. Prog Brain Res 88:533-543. CrossRef Medline

Káradóttir R, Attwell D (2006) Combining patch-clamping of cells in brain slices with immunocytochemical labeling to define cell type and developmental stage. Nat Protoc 1:1977-1986. CrossRef Medline

Kozak R, Bowman EM, Latimer MP, Rostron CL, Winn P (2005) Excito- toxic lesions of the pedunculopontine tegmental nucleus in rats impair performance on a test of sustained attention. Exp Brain Res 162:257-264. Medline

Lee CC, Sherman SM (2010) Topography and physiology of ascending streams in the auditory tectothalamic pathway. Proc Natl Acad Sci U S A 107:372-377. CrossRef Medline

LeDoux JE, Farb C, Ruggiero DA (1990) Topographic organization of neurons in the acoustic thalamus that project to the amygdala. J Neurosci 10:1043-1054. Medline

Lennartz RC, Weinberger NM (1992) Frequency-specific receptive field plasticity in the medial geniculate body induced by pavlovian fear conditioning is expressed in the anesthetized brain. Behav Neurosci 106:484. CrossRef

Llano DA, Sherman SM (2008) Evidence for nonreciprocal organization of the mouse auditory thalamocortical-corticothalamic projection systems. J Comp Neurol 507:1209-1227. CrossRef Medline

Llano DA, Slater BJ, Lesicko AM, Stebbings KA (2014) An auditory colliculothalamocortical brain slice preparation in mouse. J Neurophysiol 111: 197-207. CrossRef Medline

Llinás RR, Steriade M (2006) Bursting of thalamic neurons and states of vigilance. J Neurophysiol 95:3297-3308. CrossRef Medline

Llinás RR, Leznik E, Urbano FJ (2002) Temporal binding via cortical coincidence detection of specific and nonspecific thalamocortical inputs: a voltage-dependent dye-imaging study in mouse brain slices. Proc Natl Acad Sci U S A 99:449-454. CrossRef Medline

Luetje CW, Patrick J (1991) Both alpha- and beta-subunits contribute to the agonist sensitivity of neuronal nicotinic acetylcholine receptors. J Neurosci 11:837-845. Medline

Mansvelder HD, van Aerde KI, Couey JJ, Brussaard AB (2006) Nicotinic modulation of neuronal networks: from receptors to cognition. Psychopharmacology 184:292-305. CrossRef Medline

McCormick DA, Bal T (1997) Sleep and arousal: thalamocortical mechanisms. Annu Rev Neurosci 20:185-215. CrossRef Medline

Metherate R, Intskirveli I, Kawai HD (2012) Nicotinic filtering of sensory processing in auditory cortex. Front Behav Neurosci 6:44. CrossRef Medline

Millar NS, Gotti C (2009) Diversity of vertebrate nicotinic acetylcholine receptors. Neuropharmacology 56:237-246. CrossRef Medline

Morley BJ, Kemp GE (1981) Characterization of a putative nicotinic acetylcholine receptor in mammalian brain. Brain Res 228:81-104. CrossRef Medline

Moser N, et al. (2007) Evaluating the suitability of nicotinic acetylcholine receptor antibodies for standard immunodetection procedures. J Neurochem 102:479-492. CrossRef Medline

Nathanson JL, Yanagawa Y, Obata K, Callaway EM (2009) Preferential labeling of inhibitory and excitatory cortical neurons by endogenous tropism of adeno-associated virus and lentivirus vectors. Neuroscience 161: 441-450. CrossRef Medline

Peruzzi D, Bartlett E, Smith PH, Oliver DL (1997) A monosynaptic GABAergic input from the inferior colliculus to the medial geniculate body in rat. J Neurosci 17:3766-3777. Medline

Pinault D (2004) The thalamic reticular nucleus: structure, function and concept. Brain Res Rev 46:1-31. CrossRef Medline

Quick MW, Lester RA (2002) Desensitization of neuronal nicotinic receptors. J Neurobiol 53:457-478. CrossRef Medline

Richardson BD, Ling LL, Uteshev VV, Caspary DM (2011) Extrasynaptic GABA A receptors and tonic inhibition in rat auditory thalamus. PLoS One 6:e16508. CrossRef Medline

Rouiller EM, Durif C (2004) The dual pattern of corticothalamic projection of the primary auditory cortex in macaque monkey. Neurosci Lett 358: 49-52. CrossRef Medline

Rouiller EM, Welker E (2000) A comparative analysis of the morphology of corticothalamic projections in mammals. Brain Res Bull 53:727-741. CrossRef Medline

Sarter M, Bruno JP (2000) Cortical cholinergic inputs mediating arousal, attentional processing and dreaming: differential afferent regulation of the basal forebrain by telencephalic and brainstem afferents. Neuroscience 95:933-952. CrossRef Medline

Sarter M, Givens B, Bruno JP (2001) The cognitive neuroscience of sustained attention: where top-down meets bottom-up. Brain Res Rev 35: 146-160. CrossRef Medline

Schieber F (2003) Human factors and aging: identifying and compensating 
for age-related deficits in sensory and cognitive function. In: Impact of technology on successful aging (Schaie WK, Charness N, eds), pp 42-84.

Schofield, B., Motts, S., and Mellott, J (2011) Cholinergic cells of the pontomesencephalic tegmentum: Connections with auditory structures from cochlear nucleus to cortex. Hear Res 85-95.

Smith PH, Bartlett EL, Kowalkowski A (2007) Cortical and collicular inputs to cells in the rat paralaminar thalamic nuclei adjacent to the medial geniculate body. J Neurophysiol 98:681-695. CrossRef Medline

Smith PH, Uhlrich DJ, Manning KA, Banks MI (2012) Thalamocortical projections to rat auditory cortex from the ventral and dorsal divisions of the medial geniculate nucleus. J Comp Neurol 520:34-51. CrossRef Medline

Sottile SY, Ling L, Cox BC, Caspary DM (2017) Impact of aging on postsynaptic neuronal nicotinic neurotransmission in auditory thalamus. J Physiol 595:5375-5385. CrossRef Medline

Steriade M, McCarley RW (1990) Brainstem control of wakefulness and sleep. New York: Plenum.

Suga N, Ma X (2003) Multiparametric corticofugal modulation and plasticity in the auditory system. Nat Rev Neurosci 4:783-794. CrossRef Medline

Sun YG, Pita-Almenar JD, Wu CS, Renger JJ, Uebele VN, Lu HC, Beierlein M (2013) Biphasic cholinergic synaptic transmission controls action potential activity in thalamic reticular nucleus neurons. J Neurosci 33:20482059. CrossRef Medline

Venkataraman Y, Bartlett EL (2013) Postnatal development of synaptic properties of the GABAergic projection from the inferior colliculus to the auditory thalamus. J Neurophysiol 109:2866-2882. CrossRef Medline

Wada E, Wada K, Boulter J, Deneris E, Heinemann S, Patrick J, Swanson LW (1989) Distribution of alpha2, alpha3, alpha4, and beta2 neuronal nicotinic receptor subunit mRNAs in the central nervous system: a hybridization histochemical study in the rat. J Comp Neurol 284:314-335. CrossRef Medline

Wang F, Flanagan J, Su N, Wang LC, Bui S, Nielson A, Wu X, Vo HT, Ma XJ, Luo Y (2012) RNAscope: a novel in situ RNA analysis platform for formalin-fixed, paraffin-embedded tissues. J Mol Diagn 14:22-29. Medline

Winer JA, Larue DT (1996) Evolution of GABAergic circuitry in the mammalian medial geniculate body. Proc Natl Acad Sci U S A 93:3083-3087. CrossRef Medline

Winer JA, Diehl JJ, Larue DT (2001) Projections of auditory cortex to the medial geniculate body of the cat. J Comp Neurol 430:27-55. CrossRef Medline

Winer JA, Schreiner CE (2005) The central auditory system: a functional analysis. In: The inferior colliculus (Winer JA, Schreiner CE, eds), pp 1-68. New York: Springer.

Wingfield A, Tun PA, McCoy SL (2005) Hearing loss in older adulthood: what it is and how it interacts with cognitive performance. Curr Dir Psychol Sci 14:144-148. CrossRef

Wonnacott S (1997) Presynaptic nicotinic ACh receptors. Trends Neurosci 20:92-98. CrossRef Medline

Woolf NJ (1991) Cholinergic systems in mammalian brain and spinal cord. Prog Neurobiol 37:475-524. CrossRef Medline

Wu Y, Yan J (2007) Modulation of the receptive fields of midbrain neurons elicited by thalamic electrical stimulation through corticofugal feedback. J Neurosci 27:10651-10658. CrossRef Medline

Xiao Y, Kellar KJ (2004) The comparative pharmacology and up-regulation of rat neuronal nicotinic receptor subtype binding sites stably expressed in transfected mammalian cells. J Pharmacol Exp Ther 310:98-107. CrossRef Medline

Xu W, Orr-Urtreger A, Nigro F, Gelber S, Sutcliffe CB, Armstrong D, Patrick JW, Role LW, Beaudet AL, De Biasi M (1999) Multiorgan autonomic dysfunction in mice lacking the $\beta 2$ and the $\beta 4$ subunits of neuronal nicotinic acetylcholine receptors. J Neurosci 19:9298-9305. Medline

Yu YQ, Xiong Y, Chan YS, He J (2004) Corticofugal gating of auditory information in the thalamus: an in vivo intracellular recording study. J Neurosci 24:3060-3069. CrossRef Medline

Zhang F, Gradinaru V, Adamantidis AR, Durand R, Airan RD, de Lecea L, Deisseroth K (2010) Optogenetic interrogation of neural circuits: technology for probing mammalian brain structures. Nat Protoc 5:439-456. CrossRef Medline

Zhang Y, Yan J (2008) Corticothalamic feedback for sound-specific plasticity of auditory thalamic neurons elicited by tones paired with basal forebrain stimulation. Cereb Cortex 18:1521-1528. CrossRef Medline

Zikopoulos B, Barbas H (2007) Circuits for multisensory integration and attentional modulation through the prefrontal cortex and the thalamic reticular nucleus in primates. Rev Neurosci 18:417-438. Medline 